\title{
Contrôle des pollutions diffuses par les pesticides. Une approche coût-efficacité spatialement distribuée
}

Cost-Effectiveness Analysis for controlling Non Point Source pollution by pesticides

Jean-Marie Lescot, Paul Bordenave, Odile Leccia et Kevin Petit

\section{OpenEdition}

\section{Journals}

Édition électronique

URL : http://journals.openedition.org/economierurale/3832

DOI : 10.4000/economierurale.3832

ISSN : 2105-2581

Éditeur

Société Française d'Économie Rurale (SFER)

Édition imprimée

Date de publication : 15 février 2013

Pagination : 123-150

ISSN : 0013-0559

Référence électronique

Jean-Marie Lescot, Paul Bordenave, Odile Leccia et Kevin Petit, « Contrôle des pollutions diffuses par les pesticides. Une approche coût-efficacité spatialement distribuée », Économie rurale [En ligne], 333 | janvier-février 2013, mis en ligne le 15 février 2015, consulté le 07 mai 2019. URL : http:// journals.openedition.org/economierurale/3832 ; DOI : 10.4000/economierurale.3832 


\title{
Contrôle des pollutions diffuses par les pesticides Une approche coût-efficacité spatialement distribuée
}

\author{
Jean-Marie LESCOT, Paul BORDENAVE, Odile LECCIA, Kevin PETIT • Irstea, Unité de Recherche \\ $A D B X$, Centre de Bordeaux; Cestas.
}

La Directive cadre sur l'eau impose une stratégie complète pour améliorer l'état écologique et chimique des masses d'eau permettant la mise en place d'une politique spécifique de réduction des pollutions diffuses. Dans le but de comparer différentes mesures agro-environnementales choisies pour contrôler la pollution par les pesticides dans les eaux de surface, les auteurs proposent un cadre méthodologique pour une analyse coût-efficacité distribuée. Ils utilisent le modèle SWAT pour évaluer l'efficacité des mesures appliquées et développent un modèle bioéconomique agrégé pour évaluer les coûts de mise en place et identifier les synergies et substitutions. Cette approche est appliquée sur la partie amont du bassin du Gers dans le Sud-Ouest de la France. Les résultats montrent que le ratio coût-efficacité des mesures dépend non seulement des mesures mais aussi largement de l'endroit où elles sont appliquées.

MOTS-CLÉS : Analyse coût-efficacité, Modélisation intégrée, Pesticides, SWAT, Modélisation Bioéconomique

\section{Cost-Effectiveness Analysis for controlling Non Point Source pollution by pesticides}

The EU Water Framework Directive (2000/60/EC) requires policy to address non-point source pollution as part of an overall integrated strategy to improve the ecological and chemical status of water bodies. With the aim of comparing various agricultural measures to control pesticide pollution in surface waters, we propose a methodological framework for spatially-distributed Cost-Effectiveness analysis. We use the Soil and Water Assessment Tool (SWAT) model to assess the effectiveness of the measures applied and develop an aggregated bio-economic model to evaluate the costs of implementation and to identify synergies and trade-offs. This approach is applied to the Gers river basin in southwest France. Findings clearly demonstrated that cost and effectiveness of measures depend not only of measures themselves but largely of the location of their implementation. (JEL: Q530, Q15, Q25)

KEY-WORDS: Cost-Effectiveness analysis, Integrated modeling, Pesticides, SWAT, Bio-economic modeling

L 'intensification des pratiques agricoles au cours des dernières décennies a conduit à un usage croissant des engrais. L'usage des pesticides s'est développé en parallèle et a permis ainsi de combattre les parasites des cultures, de réduire la compétition avec les adventices et d'assurer la qualité, la sécurité et le prix des produits agricoles (Commission européenne, 2003). Cet usage important des pesticides en $\mathrm{Eu}-$ rope et notamment en France (troisième utilisateur mondial en quantité) a conduit à une pollution des sols et des eaux. Cette pollution est due à la dérive des produits pendant leur application puis à leur dispersion et lessivage dans les sols (pollutions diffuses) mais aussi aux pertes lors de leur stockage ou du nettoyage des équipements (pollutions ponctuelles).

Pour combattre ce problème de pollution des eaux, l'Union européenne a mis en place plusieurs régulations et directives telles que la Directive nitrate (91/676/EEC), la Directive cadre sur l'eau (2000/60/EC), 
et récemment la Directive pesticide (2009/128/EC).

La conformité avec la Directive cadre sur l'eau (DCE) implique une réduction de l'impact des pressions agricoles. Les mesures agro-environnementales prévues dans ce cadre ont supporté les engagements à réduire l'utilisation des pesticides, à promouvoir la protection phytosanitaire intégrée et la conversion à l'agriculture biologique. Par ailleurs, la participation du public à la gestion de l'eau est requise dans les conventions internationales (Organisation des Nations Unies, 2000 ; Convention d'Aarhus, UNECE, 1998 ; Directive 2000/60/EC) et se doit d'être significative lorsque les questions sont complexes et les incertitudes élevées.

Les caractéristiques de la production agricole, comme les sols, les pentes, les systèmes de culture ou leur emplacement par rapport au système hydrographique peuvent varier à l'intérieur d'un bassin versant et entre sous-bassins d'un bassin hydrographique. Aussi, les mesures agroenvironnementales définies au niveau national ou régional peuvent conduire à des résultats extrêmement différents en termes de coûts de mise en place et d'efficacité environnementale. En plus de ces incertitudes sur les coûts et efficacités des programmes environnementaux, les budgets alloués à leur mise en œuvre sont limités. Se pose alors la question de savoir comment utiliser les fonds disponibles de manière efficace et pertinente.

Des travaux antérieurs montrent que le ciblage des mesures environnementales peut améliorer l'efficacité du contrôle de la pollution diffuse en se concentrant sur des zones critiques (Dickinson et al., 1990). Néanmoins, les coûts de mise en œuvre dans ces zones ont besoin d'être examinés. Pour aborder ces questions, l'étude présentée ici interroge l'utilisation possible d'une Analyse coût-efficacité (ACE) spatialement distribuée. Nous illustrons comment l'usage d'outils de modélisation pour l'analyse des différents impacts et des coûts des mesures pourrait aider à la mise en place des programmes environnementaux. Le cadre proposé (figure 1) est une approche ascendante se concentrant et sur le coût d'implémentation et sur l'efficacité de mesures au niveau de la parcelle, sousbassin puis bassin versant.

La première partie de notre article présente la méthodologie utilisée par la modélisation agro-hydrologique et bioéconomique pour l'évaluation des mesures environnementales. Dans la seconde partie, ce schéma cadre proposé est appliqué à un petit bassin hydrographique du SudOuest de la France pour évaluer certaines mesures agro-environnementales traitant principalement des changements de pratiques agricoles. La mise en application des modèles est présentée dans les sections 5 et 6 et les résultats dans les sections 7 et 8. L'ACE occupe la section 9, suivie dans la section 10 d'une discussion sur le cadre proposé comme outil d'aide à la décision dans la gestion participative de bassins versants.

\section{Modélisation}

L'efficacité des mesures peut être évaluée au regard d'objectifs intermédiaires (diminution de la pression) par l'utilisation d'indicateurs ou au regard d'objectifs finaux (impacts) à l'aide de modèles. Dans la mesure où les objectifs de la DCE pour 2015 sont la restauration du bon état écologique des masses d'eau, ce sont bien les impacts des mesures environnementales qui doivent être évalués.

La modélisation hydrologique fournit alors un moyen d'évaluer les effets de ces mesures sur une longue période de temps couvrant plusieurs années de mise en œuvre.

Il est attendu aussi à ce que les résultats des modèles soient une source d'information objective sur les impacts à court et 


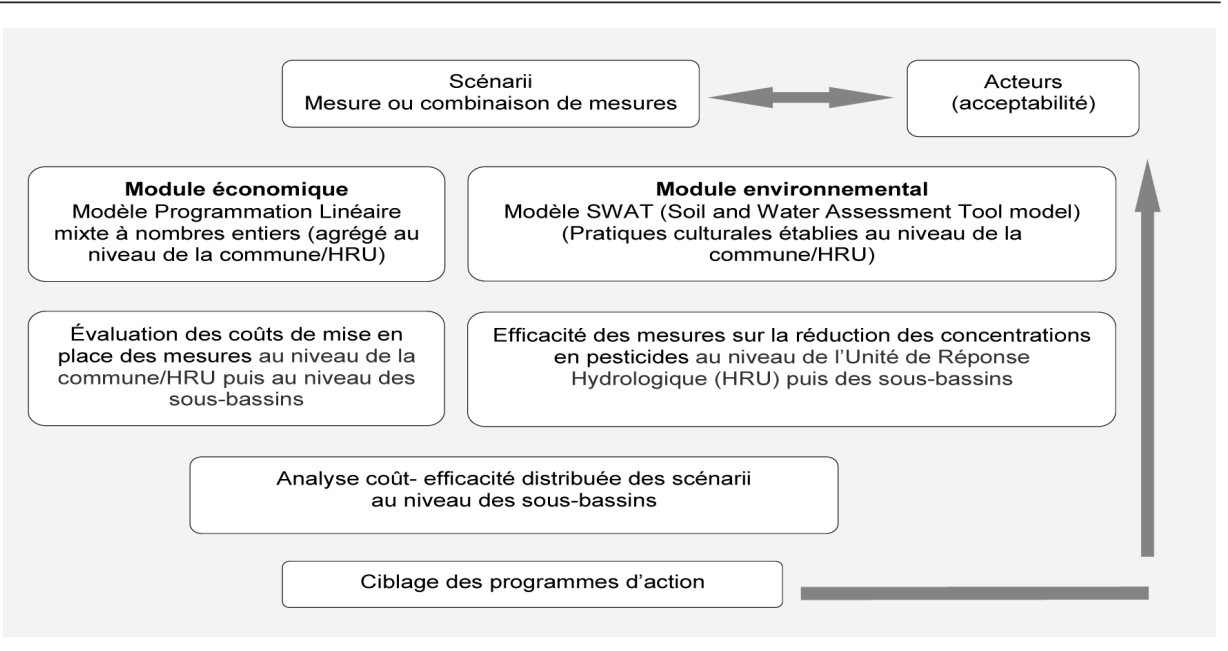

Source : Les auteurs

long terme. Cette information peut alors être utilisée comme aide à la décision même si l'utilisation des modèles dépend toujours des hypothèses et priorités des modélisateurs (Alkan Olsson et Anderson, 2007).

La modélisation intégrée que nous proposons ici, est ce que Brouwer et Hofkes (2008) nomment un méta-modèle. Dans ce type de modèle, les résultats de simulations des sous-modèles bio-géophysiques et économiques sont liés, mais la résolution n'est pas simultanée. Notre approche est basée initialement sur l'utilisation du modèle semi-distribué SWAT (Soil and Water Assessment Tool). La partie économique a de ce fait été développée pour correspondre aux caractéristiques du modèle SWAT et le calcul des coûts est réalisé à un niveau similaire à celui de l'évaluation des effets environnementaux (sous-bassin hydrographique ou bassin versant). Le modèle SWAT est considéré comme l'un des modèles les plus appropriés pour prédire les effets à long terme de la gestion des terres sur les charges en sédiments et produits chimiques agricoles dans l'eau sur de grands bassins versants complexes avec des conditions variables de sols, d'utilisation des terres et des systèmes de cultures (Arnold et Fohrer 2005; Neitsch et al., 2005). Il a été choisi pour son aptitude à simuler et les flux de pesticides à l'échelle du bassin versant et leurs concentrations dans les cours d'eau ainsi que pour son potentiel à simuler les pratiques agricoles. Le bassin hydrographique est subdivisé en sous-bassins sur la base du nombre de tributaires. Les sous-bassins sont ensuite désagrégés en Unités de réponse hydrologique (HRU) homogènes par l'occupation du sol, leurs caractéristiques et les pratiques culturales. Les HRUs, de ce fait différents en taille, sont les unités spatiales où les flux d'eau et de nutriments verticaux, latéraux et sous-latéraux sont calculés puis agrégés pour chaque sous-bassin. L'eau et les pesticides provenant des HRU vers les sous-bassins sont ensuite acheminés vers les exutoires des bassins hydrographiques (Neitsch et al., 2005).

Les pratiques culturales sont définies au niveau de la HRU par les opérations culturales spécifiques (début et fin de la période de culture, calendrier des opérations culturales, quantités et calendrier des 
apports d'engrais et pesticides, gestion de l'irrigation).

Étant donné le délai entre causes et effets, mise en place de la mesure et réponse au niveau du bassin versant, l'efficacité doit être évaluée sur une longue période avec des mesures appliquées chaque année (Roa-García et Weiler, 2010 ; GascuelOdoux et al., 2010). Les lecteurs pourront se référer à Gassman et al., (2007) pour une revue du modèle SWAT et de ses applications.

Le modèle économique développé dans le cadre de cette étude, quant à lui, cherche à savoir si l'objectif de réduction des pesticides peut être atteint au moindre coût. Comme les coûts marginaux d'application des mesures ne sont pas égaux (entre mesures et pour une même mesure suivant l'endroit où elle est appliquée), il est théoriquement possible d'obtenir le même niveau de réduction de pollution de l'eau au moindre coût en passant de mesures coûteuses à des mesures moins onéreuses (Brouwer et de Blois, 2008) et pour une mesure identique en passant d'un lieu à l'autre.

Pour le calcul des coûts, l'approche économique classique des budgets partiels, malgré son intérêt dans le processus de prise de décision des agriculteurs présente cependant un inconvénient majeur. Les budgets partiels peuvent en effet ne pas refléter des décisions efficaces d'un point de vue économique. Pour dériver une courbe significative des substitutions, toute méthode économique doit permettre d'échanger un ensemble de stratégies facultatives dans un cadre de prise de décision (Lee, 1998).

La méthode d'optimisation économique est ainsi considérée comme la plus pertinente pour l'analyse des coûts en raison de la capacité qu'elle offre de substituer des stratégies. Les modèles en programmation mathématique ont de plus, la capacité unique de lier des éléments économiques avec des éléments agronomiques et biophysiques (Buysse et al., 2007).
Recourir à des exploitations représentatives (moyennes) ou types (modales) est généralement la façon la plus satisfaisante de modéliser les exploitations agricoles. Cette pratique expose néanmoins à des biais potentiels lors de l'agrégation de données d'exploitations ou de l'utilisation au niveau de l'exploitation de données agrégées (Day, 1963). En outre, recourir à des exploitations représentatives ou types laisse ouverte la question de la distribution spatiale des exploitations. L'autre forme d'agrégation que nous proposons pour dépasser ces problèmes revient à modéliser l'ensemble des exploitations d'une unité spatiale comme si elles ne représentaient qu'une une seule méga-exploitation. Cette solution même si elle peut surestimer la flexibilité et la coordination des productions agricoles est toutefois largement acceptée comme moyen de modéliser de grandes zones (O'Callaghan, 1996) et appropriée pour des zones relativement petites comme les sous-bassins versants ou les HRU.

Le sous-bassin hydrographique et/ou le bassin versant sont les échelles adéquates pour l'évaluation de l'efficacité des mesures et appropriées pour représenter les processus physiques. Le calcul des coûts doit parfois dans un premier temps être réalisé à une autre échelle plus adaptée aux données disponibles. Les coûts sont alors évalués au niveau du bassin versant par répartition proportionnelle à la superficie de la surface appartenant à chaque sous-bassin. La modélisation économique présentée ici a été développée au niveau de la commune pour le calcul des coûts de mise en œuvre. Dans l'avenir il est prévu de réaliser les calculs à la même unité spatiale que celle utilisée pour la modélisation hydrologique (HRU) permettant ainsi d'introduire l'hétérogénéité spatiale des rendements simulés par le modèle de croissance des plantes intégré à SWAT. Enfin, pour que les coûts soient appropriés à la période de mise en place des mesures, les estimations annuelles 
sont agrégées sur la durée de la simulation hydrologique en utilisant la somme actualisée des coûts annuels. L'analyse des coûts a donc commencé par le développement d'un modèle spatialisé en programmation linéaire mixte à nombres entiers (détaillé dans l'annexe) utilisant GAMS (Brooke et al. 1988 ; Mc Carl, 2009).

Une fois l'efficacité et les coûts évalués, d'autres questions se posent alors : Comment atteindre les objectifs des mesures avec les fonds disponibles? Est-ce qu'il n'y aurait pas d'autres moyens moins coûteux d'atteindre ces objectifs ? Ces questions peuvent être traitées par l'ACE, méthode appropriée pour évaluer les mesures visant à réduire les pollutions diffuses en raison de la difficulté et du peu de fiabilité à déterminer des fonctions de dommage. $\mathrm{Si}$ l'ACE ne peut pas déterminer la valeur globale d'une mesure unique, elle est toutefois particulièrement utile pour comparer deux mesures ayant des impacts potentiels similaires. Nous utilisons ainsi un indicateur $R$ ou ratio Coût-efficacité (CE), défini au niveau du sous-bassin ou d'une zone donnée du bassin comme le rapport entre d'une part la somme actualisée des coûts annuels au cours de la période de mise en œuvre et d'autre part, la réduction des concentrations de pesticides qui en résultent. $\mathrm{Ce}$ ratio permet ainsi de classer les mesures en termes de coût unitaire par unité de réduction de concentration en pesticide.

$$
\begin{gathered}
R=\frac{\sum_{\mathrm{t}=1}^{\mathrm{T}} \mathrm{CA}_{\mathrm{t}}(1+\mathrm{i})^{-\mathrm{t}}}{\left(\left[\mathrm{C}_{0}\right]-\left[\mathrm{C}_{\mathrm{s}}\right]\right)} \\
\operatorname{avec} \sum_{\mathrm{t}=1}^{\mathrm{T}} \mathrm{CA}_{\mathrm{t}}(1+\mathrm{i})^{-\mathrm{t}}:
\end{gathered}
$$

Somme actualisée des coûts annuels $(€)$ de mise en place de la mesure (surface donnée); $\left[\mathrm{C}_{\mathrm{s}}\right]$ : Concentration moyenne sur les dix dernières années de la simulation hydrologique (mg. $\mathrm{l}^{-1}$, avec application de la mesure chaque année (sur la surface donnée) ; $\left[\mathrm{C}_{0}\right]$ : concentration initiale $\left(\mathrm{mg} . \mathrm{l}^{-1}\right)$; $\mathrm{CA}_{t}$ : coûts annuels ; $\mathrm{T}$ : nombre d'années de la période de simulation; i : taux d'escompte.

\section{Mesures agro-environnementales}

Avec la réforme de la PAC en 1992, puis celle de 2003 la mise en œuvre de programmes agro-environnementaux est devenue obligatoire pour les États membres. Les mesures proposées dans le cadre de ces programmes pourraient aider à atteindre les objectifs de la DCE de même que d'autres mesures définies par les parties prenantes (en particulier les Agences de l'eau). Les mesures promues sont la rotation des cultures, la couverture du sol en hiver et les cultures intermédiaires pour limiter la lixiviation pendant les saisons humides, les bandes enherbées non fertilisées le long des cours d'eau et des fossés pour leur effet «tampon », une bonne gestion des sols et la restriction des cultures en forte pente. De telles mesures initialement considérées pour limiter l'érosion des sols et la pollution par les nitrates pourraient dans le même temps réduire les transferts de pesticides dans le milieu. Les agriculteurs qui s'engagent à adopter ces mesures pendant une période minimale de cinq ans reçoivent en retour des paiements qui sont censés compenser les coûts supplémentaires et la perte de revenu qui en résulte. Les compensations monétaires administratives sont cependant principalement basées sur des considérations budgétaires avec un taux de compensation constant par hectare. Par ailleurs, la nouvelle Directive cadre européenne sur les pesticides (2009/128/ $\mathrm{CE})$ rend désormais obligatoire pour tous les États membres la mise en place de plans d'action, impliquant tous les acteurs pertinents dans le processus. Toutefois, le développement de programmes environnementaux visant à réduire les effets 
des pesticides utilisés en agriculture reste compliqué par les questions spatiales, temporelles et d'hétérogénéité technologique. À cela s'ajoutent les préoccupations quant aux délais entre pratiques agricoles et dommages. Pour finir, ces relations sont soumises à un certain nombre de facteurs stochastiques hors du contrôle de l'agriculteur ; ainsi les charges en pesticides augmentent généralement avec l'intensité des pluies à des moments inopportuns.

\section{Application au bassin versant du Gers amont}

La méthodologie proposée a été appliquée à une partie du bassin de la rivière Gers, sous-bassin du bassin hydrographique de la Garonne dans le Sud-Ouest de la France (figure 2). Le bassin versant du Gers long de $176 \mathrm{~km}$, draine une zone de $1230 \mathrm{~km}^{2}$. La région qui s'étend du sud au nord a un paysage de collines et est parsemée par un total de 17 petites rivières et ruisseaux ${ }^{1}$ qui, en raison de sa structure morphologique, ont exclusivement de très petits bassins versants.

Les processus hydrologiques sont caractérisés par des transferts superficiels alimentés par l'eau de nappes peu profondes à capacité limitée. Les débits d'eau ne seraient pas possibles toute l'année en conditions normales si un système de barrages en amont réalimentant les rivières pendant les périodes d'étiage (système Neste) n'avait pas été créé, dans les années 1960, pour soutenir les étiages, améliorer la disponibilité de l'eau tant à des fins agricoles que pour l'eau potable. La zone concernée par l'étude présentée ici est limitée à la partie amont (département du Gers) du bassin de la rivière Gers. Elle est consacrée essentiellement à l'agriculture et notamment aux grandes cultures (maïs grain, irrigué et en sec, ou fourrage, blé

1.Zone des coteaux de Gascogne d'une superficie de $9000 \mathrm{~km}^{2}$. tendre, blé dur, tournesol, prairies permanentes et temporaires). Les quelques activités d'élevage qu'on y rencontre sont principalement représentées par des systèmes laitiers et vaches allaitantes. Les types de sols ont des caractéristiques différentes. On y retrouve des alluvions, des colluvions et des sols limoneux et argileux. La pollution de l'eau par les pesticides est un sujet de préoccupation avec des concentrations plus élevées que les normes eau potable de l'UE (au cours des dernières années, $65 \%$ des échantillons d'eau ont en moyenne des concentrations supérieures à $0,1 \mathrm{mg} . \mathrm{l}^{-1}$ par pesticide et $29 \%$ ont des concentrations supérieures à $0,5 \mathrm{mg} . \mathrm{l}^{-1}$ pour l'ensemble des pesticides). Cette zone, en raison des problèmes récurrents de qualité des eaux, fait l'objet d'un plan d'action territorial (PAT ${ }^{2}$ Gers amont).

Les mesures environnementales évaluées ont été sélectionnées selon plusieurs critères: leur efficacité potentielle à améliorer la qualité de l'eau vis-à-vis des pesticides, leur mise en œuvre déjà effective partiellement sur la partie amont de la rivière Gers, même si dans la plupart des cas pour répondre à d'autres problèmes environnementaux comme l'érosion ou le lessivage de l'azote. À la suite de réunions avec tous les acteurs, elles sont apparues comme les plus susceptibles d'être acceptées et réalisées par les agriculteurs. Par la suite, nous appellerons scénario, toute mesure appliquée soit sur l'ensemble des zones prioritaires

2. Le Plan d'action territorial (PAT) Gers amont est un programme d'actions soutenu par l'Agence de l'eau Adour-Garonne dont le but est de réduire la pollution des ressources en eau (rivière Gers ou nappe phréatique) utilisées pour la production d'eau potable. Un PAT est porté par une structure locale (Collectivité, Chambre d'agriculture...) qui assure l'élaboration, l'animation et le suivi d'un ensemble de mesures pluriannuelles sur un périmètre défini, en concertation. Le PAT Gers amont est porté par le Conseil général du Gers. 
Figure 2. Principales étapes de la méthodologie appliquée pour l'ACE des mesures environnementales

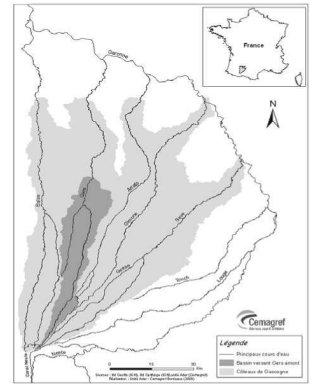

Bassin versant étudié (gris foncé) dans la zone des Coteaux de Gascogne (en gris clair)

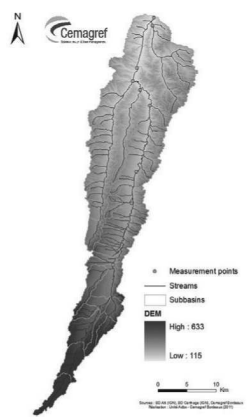

Modèle Numérique de Terrain (MNT) et points de mesure

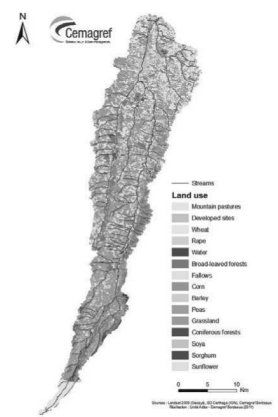

Utilisation des terres

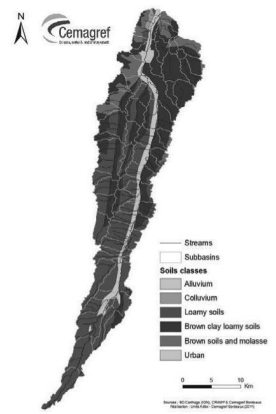

Sols

\section{Pratiques}

Définition des rotations types par communes du bassin versant Analyse en Composantes Principales et Classification pour identifier les communes ayant des caractéristiques homogènes pour les activités de production en termes d'utilisation du sol et de pratiques

\section{Définition de scenarii}

Mesure agro-environnementale (seule ou combinaison) et/ou autres mesures définies par les acteurs et/ou l'Agence de l'eau

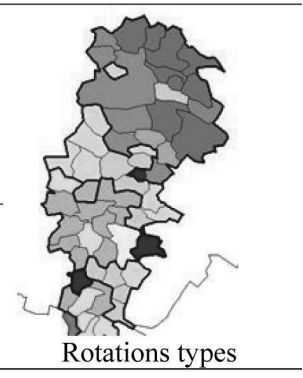

Modélisation SWAT - Évaluation de l'efficacité au niveau de sous-bassins

Efficacité $_{\rho_{(\rho)}}=\left(1-\frac{\left[C_{s}\right]_{\mu g l^{-l}}}{\left[C_{\theta}\right]_{\mu g l^{-1}}}\right) \times 100$

$\left[C_{s}\right]_{\mu g I^{1} \text { concentration moyenne sur les dix dernières }}$

$\left[C_{0}\right]_{\mu g l^{-1}}$ concentration scénario de référence

Modélisation bio économique - Calcul du coût direct de mise en place des mesures au niveau de la commune

$$
\operatorname{Max} \Pi_{c}(X) \quad \forall c
$$

sous contraintes de mesure, contraintes de surface agricole utile, de surface irrigable,

de prairies permanentes, de rotations et d'élevage (alimentation, gestion du troupeau).

$$
\Pi_{c}(X)=\pi_{m 1, c}+\pi_{m 2, c}
$$

$\Pi_{C}(X)$ : profit obtenu en choisissant $\left(\pi_{m 2, c}\right)$ ou pas $\left(\pi_{m l, c}\right)$ la mise en place de la mesure

Cartographie de la dispersion des ratios Coût-Efficacité au niveau des sous bassins voir figures $6 a, b, c$
Comparaison (Coût, Efficacité et ratios CoûtEfficacité) des mesures agro environnementales voir tableaux 
(ZP) (définies pour leur vulnérabilité3) soit sur la totalité de la zone Gers amont (GA). Les scenarii évalués (tableau 1) sont donc les suivants : une zone tampon herbacée le long des cours d'eau avec différentes variantes en fonction de la largeur de la bande $(10 \mathrm{~m}$ et $20 \mathrm{~m})$, la zone où les mesures sont appliquées (sur l'ensemble de la zone GA ou seulement sur les zones prioritaires) et basées soit sur le réseau hydrographique IGN soit sur un réseau hydrographique étendu (scénarii BS) ; l'abandon du désherbage chimique au profit du désherbage mécanique avec trois passages au cours de la période de végétation et aucune application d'herbicides (scénario $M W$ ) ; la modification des rotations des cultures avec leur rallongement et une succession d'au moins 4 cultures différentes (scénario LR); une culture dérobée (ray-grass) au cours de l'inter période (de la récolte au semis de la culture suivante) (scénario CC); le passage de cultures arables à des prairies temporaires (scénario $S G L$ ).

\section{Évaluation de l'efficacité avec le modèle SWAT}

Pour évaluer l'efficacité des scenarii, nous avons utilisé le modèle SWAT2009 avec ArcSWAT $^{4}$. L'efficacité est présentée en termes de réduction relative d'un ou de plusieurs polluants particuliers suite à la mise en œuvre de la mesure. La concentration de

3. Une zone critique est généralement définie comme la plus sensible ou vulnérable dans le bassin versant et contribuant le plus à la pollution de l'eau. Les types de sols identifiés comme présentant des risques élevés de transfert des pesticides seront classés comme des zones critiques. La vulnérabilité définie par croisement des zones critiques avec des indicateurs de pression (cultures, itinéraires techniques définissant le nombre d'applications de pesticides) sert à définir les zones prioritaires où des actions sont menées. Ont été utilisées les zones prioritaires définies initialement par l'Agence de l'eau Adour-Garonne.

4. Système d'information géographique Arcview 3.2 interfacé avec SWAT version 2005 . référence du scénario de base est utilisée comme constante de normalisation. La réduction de concentration est calculée à l'exutoire de chaque sous-bassin et du bassin versant. L'étendue limitée des plages de concentration permet l'hypothèse d'une réduction linéaire de la pollution. Une telle simplification serait cependant contestable sur des valeurs plus étendues.

Pour l'ACE, sont utilisés les changements absolus comme dénominateur du ratio coût-efficacité $\mathrm{R}$ (supra). L'efficacité est évaluée lorsque les mesures sont appliquées à l'ensemble du bassin Gers amont et aussi, pour certaines mesures, seulement sur les zones prioritaires. La réduction des concentrations est évaluée sur une période de 25 ans, les mesures étant appliquées chaque année. Nous retenons les valeurs moyennes de concentration en pesticides calculées sur la base des dix dernières années de la période de modélisation.

\section{Mise en place du modèle SWAT}

La situation actuelle (scénario 0), considérée comme le scénario de référence, est préalablement définie en supposant que la mesure obligatoire des bandes enherbées d'une largeur de 5 mètres de part et d'autre d'un cours d'eau, sur zones prioritaires est effectivement mise en place sur le bassin versant.

Les données utilisées pour développer les fichiers d'entrée SWAT sont diverses : un Modèle numérique de terrain (MNT) d'une résolution de 25 mètres de l'Institut géographique national (IGN), Corine Landcover 2000 pour la couverture du sol «fixe », le Recensement général de l'agriculture (RGA, 2000) par commune pour la couverture du sol agricole «non fixe». Ces couvertures ont été affinées spatialement par de l'analyse d'images satellites Spot classifiées supervisées par la méthode des K-means ${ }^{5}$. Le réseau hydrographique initial de la base de données nationale

5.Algorithme de partitionnement de données. 
RECHERCHES

Jean-Marie LESCOT, Paul BORDENAVE, Odile LECCIA, Kevin PETIT

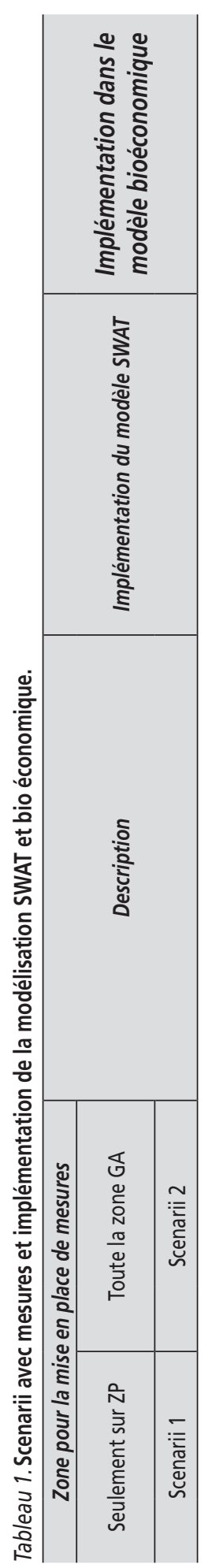

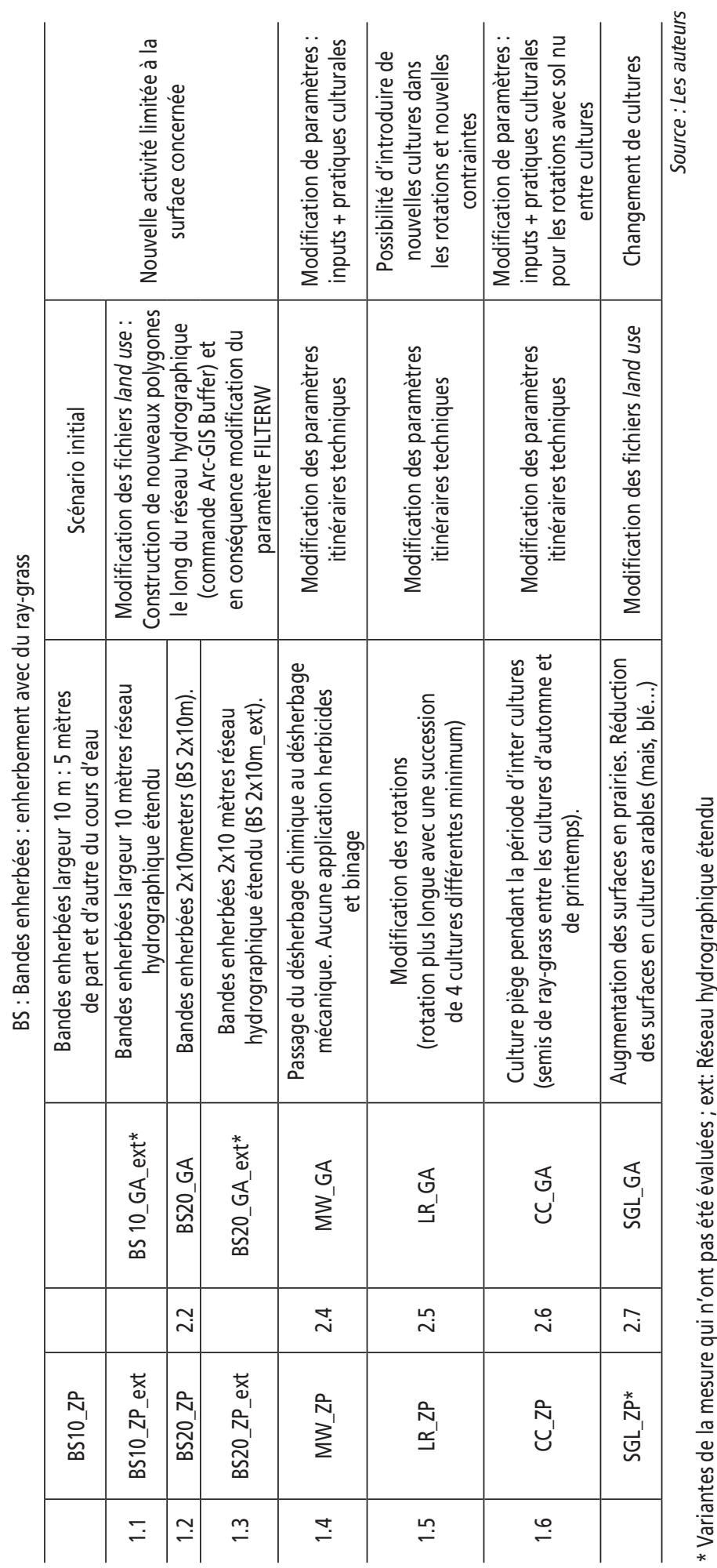

Économie Rurale 333/Janvier-Février 2013 • 127 
Carthage est intégré au MNT avec Arcview pour créer un réseau plus précis (réseau étendu prenant en compte les ruisseaux et fossés) destiné à être utilisé pour certains scenarii. Les cartes numérisées du sol proviennent de l'Inventaire, gestion et conservation des sols (IGCS) de l'Institut national de la recherche agronomique (INRA), tandis que les données physico-chimiques des sols sont fournies par la Chambre régionale d'agriculture de la Chambre régionale d'agriculture Midi-Pyrénées (CRAMP). Les valeurs météorologiques utilisées sont celles des stations Météo France présentes sur la zone Gers amont (Auch, l'Isle Jourdain, Lannemezan et Masseube). L'information sur les pratiques provient de références régionales fournies par la CRAMP (références technico-économiques en systèmes de grandes cultures, 2006 ; Systèmes de production bovins, 2006) et par le Centre de gestion local (Centre de gestion conseil Gascogne Adour, 2005).

\section{Pratiques culturales}

Avant leur utilisation comme données d'entrée de SWAT, les pratiques ont été comparées pour validation avec l'information sur les pratiques des agriculteurs locaux obtenue par enquêtes et expertises (quantités et calendrier des pratiques culturales et traitements phytosanitaires). Par souci de simplification, un seul itinéraire technique standard est attribué à une culture et lorsque celle-ci est intégrée dans une rotation, les différentes opérations techniques sont adaptées en fonction des cultures précédentes et suivantes. Au sein du bassin versant, la surface agricole des communes varie entre 2,1 et $28,5 \mathrm{~km}^{2}$ (surface médiane $6,9 \mathrm{~km}^{2}$ ) représentant un nombre d'exploitations agricoles en général faible (19 exploitations en moyenne, écart-type $=11$ ) et une superficie moyenne de 52 ha (écart-type $=17$ ).

En raison de l'absence de données exhaustives sur les zones du bassin versant, nous avons d'abord simplifié l'utilisation du sol issue de la classification d'images satellites Landsat afin de réduire le nombre de variables et de détecter une structure dans les relations entre ces variables. Nous avons combiné une analyse en composantes principales (ACP) et une Classification ascendante (CA) pour identifier les communes aux caractéristiques homogènes par les activités de production en termes d'utilisation du sol (cultures) et de pratiques (gestion des rotations). Quatorze classes initiales d'utilisation des terres (soja, sorgho, colza, jachère, maïs, pois, blé et orge, tournesol, herbages, arbres à feuilles caduques, conifères, masses d'eau, structures construites, indéfini ${ }^{6}$ ) ont été définies initialement.

Une ACP est effectuée sur les 1385 communes de la Région Midi-Pyrénées avec 10 variables de même pondération pour les différents usages du sol agricole. À partir de l'arborescence de la classification effectuée sur les sept premiers facteurs représentant $90,43 \%$ de la variance totale, nous avons obtenu 11 classes de rotation pour les cultures de toutes les communes de la zone Gers amont (supra, figure 2). Les classes de rotations sont: tournesol blé tendre ; maïs irrigué/blé tendre/tournesol/blé dur; tournesol/blé tendre/colza/blé tendre, blé tendre/prairies temporaires ; maïs/maïs/ blé tendre, maïs fourrager prairies temporaires; maïs/ blé tendre tournesol/blé dur ; maïs/blé tendre ; maïs maïs/soja ; maïs/maïs ; tournesol/blé dur colza/blé tendre. Pour la modélisation économique et le calcul des coûts, nous avons pris en compte uniquement les principales rotations identifiées pour chaque commune. Nous avons ensuite considéré que la rotation principale est appliquée sur l'ensemble des terres cultivables de la commune.

6. Indéfini : La catégorie « indéfini » fait référence à la classification erronée des pixels. 
Modélisation des débits

et des transferts de pesticides

Le modèle SWAT a été calibré sur la période 1985-1995 et la validation effectuée pour la période 1995-2005. Les données sur les débits mesurés et des analyses statistiques ont été utilisées pour vérifier les simulations. Une analyse manuelle de sensibilité a d'abord été effectuée selon une méthode semblable à celle proposée par Ullrich et Volk (2009). Les paramètres identifiés les plus sensibles (CN2 ${ }^{7}$, USLE-P ${ }^{8}$, FILTERW $^{9}$ ) ont été étalonnés à partir de la comparaison avec les données de mesure (flux d'eau, charge de sédiments et flux de pesticides) à quatre points de mesure du bassin versant. Les valeurs de débit prévues par le modèle SWAT correspondent généralement bien avec les valeurs observées pour l'étalonnage et la validation. Les coefficients de corrélation sont $\mathrm{R}^{2}=0.80$ (étalonnage) et $\mathrm{R}^{2}=0.72$ (validation) avec un indice d'efficacité Nash-Suttcliffe (NSE) de 0.65 (étalonnage) et 0.63 (validation).

Pour la modélisation des transferts de pesticides, nous avons d'abord établi, à partir d'une enquête effectuée sur 50 exploitations à l'intérieur de la zone Gers amont, l'ensemble des substances actives appliquées ainsi que leur fréquence d'utilisation pour chacune des cultures (blé tendre, blé dur, tournesol, maïs, colza et soja). Afin de réduire les temps de calcul, nous avons

7.CN: Le nombre de courbe de ruissellement (Runoff Curve Number), appelé aussi Nombre de courbe (ou simplement $\mathrm{CN}$ ) est un paramètre empirique utilisé en hydrologie pour prévoir les flux/écoulements directs ou l'infiltration à partir des excès de pluie. Cette méthode du nombre de courbe, développée aux États-Unis par 1'USDA Natural Resources Conservation Service est une méthode empirique efficace et largement utilisée pour déterminer la quantité approximative de ruissellement direct à partir d'un événement pluvieux sur une zone donnée.

8. Équation universelle d'érosion des sols.

9. Largeur de la bande tampon enherbée. réduit le nombre de substances actives aux molécules les plus largement utilisées en conservant la dose moyenne appliquée (moyenne arithmétique). Lorsqu'une classe chimique est largement utilisée (fongicides des groupes Sulfonylurées, Triazoles et Strobilurines ou herbicides avec un mélange de 3 ou 4 substances actives), nous avons défini une nouvelle « Matière active moyenne » (MAM), moyenne par ses propriétés physiques et chimiques $\left(\mathrm{Koc}^{10}\right.$, DT50 ${ }^{11}$ et solubilité) pondérée, dans les cas de mélanges de substances actives, par leur concentration relative dans le produit commercial utilisé. Les simulations sont effectuées pour chacune de ces 4 MAM et la somme de leurs concentrations quotidiennes simulées avec SWAT est utilisée comme résultat. Le scénario de référence permet alors de définir les nouveaux scenarii intégrant la mise en place des mesures agro-environnementales proposées.

\section{Vérification/Calibration des pesticides}

Les concentrations en pesticides ont été analysées sur quatre points de mesure le long de la rivière Gers. Nous avons également utilisé les analyses d'eau effectuées de 2005 à 2008 (4 à 5 analyses par an) pour 15 points de mesures sur les principales rivières de la zone des Coteaux de Gascogne dans le cadre d'une autre étude Irstea (Morin et al., 2009). La fréquence d'échantillonnage est néanmoins trop faible pour une calibration ou une validation précise à un pas de temps quotidien ou mensuel. Ces valeurs ont néanmoins été utilisées pour comparer le classement des concentrations annuelles (somme de molécules) mesurées in situ au classement des concentrations simulées sur les mêmes points. À cette fin, le modèle SWAT a été

10. Coefficient d'absorption normalisé par la fraction de matière organique du sol.

11. Durée de demi-vie de disparition DT50 (disp.) ou de dégradation DT50 (dégrad.) de la quantité de pesticides apportée au milieu. 


\section{Contrôle des pollutions diffuses}

mis en œuvre sur l'ensemble de la zone des Coteaux de Gascogne (figure 3) puis calibré afin de reproduire la concentration annuelle totale en pesticides $\left(1.2 \mu \mathrm{g} .1^{-1}\right)$ à l'exutoire de la zone Gers amont (point de mesure de Roquelaure). Nous avons ensuite comparé le classement relatif de ces points au regard de leur concentration annuelle moyenne le long de chaque cours d'eau de la région. Si les concentrations moyennes des simulations et les valeurs mesurées diffèrent parfois fortement, le classement en fonction des concentrations des points de mesures simulés correspond exactement au classement des points effectivement mesurés et ce pour tous les points reproduisant ainsi les gradients de concentration le long des cours d'eau. Les différences entre concentrations simulées et concentrations mesurées n'impliquent toutefois pas que la calibration du modèle soit mauvaise du fait de l'incertitude sur les mesures ellesmêmes (liée à leur fréquence et au nombre de valeurs par mois ou par année).

Figure 3. Flux annuels moyens en pesticides totaux $\left(\mathrm{mg}_{\mathrm{h}} \mathrm{ha}^{-1} \cdot \mathrm{an}^{-1}\right)$ des Unités de réponse hydrologiques vers les principaux cours d'eau des Coteaux de Gascogne - Modélisation SWAT scénario initial - moyenne sur 15 ans (1994-2009)
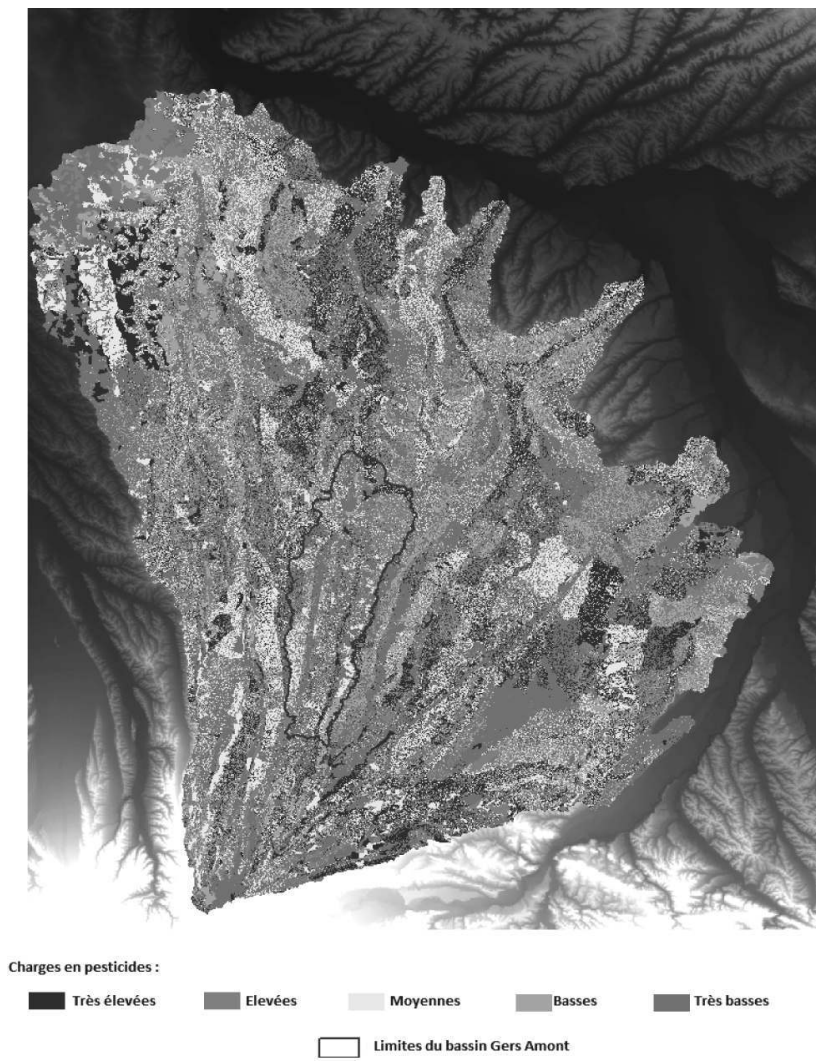


\section{Évaluation des coûts Modélisation économique}

Comme indiqué au $\$ 2$, le modèle agrégé en programmation linéaire mixte traite chaque commune comme une seule grande exploitation. Le niveau de la commune a été choisi pour des questions de disponibilité des données mais dans les développements en cours de cette méthode, c'est bien l'HRU qui est le niveau de calcul retenu. Ce modèle simule pour chaque commune, les surfaces d'utilisation des terres agricoles et calcule les coûts directs additionnels que l'exploitation-commune aurait à supporter suite à la mise en place des mesures. Pour l'ACE, les coûts évalués au niveau de la commune sont ensuite ramenés au niveau des sous-bassins en les affectant au prorata de la surface de la commune appartenant au sous-bassin.

L'objectif est de maximiser la marge brute totale au niveau communal pour les cultures et les activités d'élevage. On fait l'hypothèse que les exploitations agricoles n'ont pas d'action sur les prix (price takers) et qu'elles maximisent l'Utilité espérée dans leurs choix de production et pratiques, et dans la sélection ou non d'une mesure. Les ratios entre inputs et outputs sont supposés constants (fonctions type Leontief), comme les prix (valeurs moyennes de l'année en cours). Les mesures agro-environnementales sont introduites dans le modèle bio économique soit comme de nouvelles activités (bandes tampons herbacées, prairies) soit en modifiant les paramètres relatifs aux pratiques (tableau 1).

Nous supposons que les niveaux d'incitation liés à une mesure et nécessaires pour la faire apparaître dans les solutions optimales modélisées peuvent être considérés comme représentant les coûts directs de la mise en œuvre étant donné que les coûts fantômes (shadow costs) sont considérés comme les coûts directs de l'activité (avec mesure) non optimale. Lorsqu'une exploitation agricole choisit une mesure, elle y alloue une partie des terres et ces terres ne peuvent pas être sélectionnées pour une autre mesure. Le modèle peut ainsi être perçu comme un modèle de répartition des terres entre différentes unités spatiales. Le problème de maximisation de l'Utilité par commune est donné par :

$\operatorname{Max} \Pi_{c}(X) \quad \forall c$

$$
\begin{aligned}
& \Pi_{c}(X)=\pi_{m 1, c}+\pi_{m 2, c} \\
& \pi_{m 1, c}=\sum_{i} \sum_{p}\left(y_{i, p, m 1, c} \times p_{i}-c v_{i, p, m 1}\right) \times X_{i, p, m 1, c}+\sum_{l} \sum_{p}\left(y_{l, p} \times p_{l}-c v_{l, p}\right) \times X_{l, p, c} \\
& \pi_{m 2, c}=\left[\sum_{i} \sum_{p} X_{i, p, m 2, c} \times\left(y_{i, p, m 2} \times p_{i}-c v_{i, p, m 2}\right)\right]+\left[i n c_{m 2} \times X_{m 2, c}-C_{m 2, c}\left(X_{m 2, c}\right)\right]
\end{aligned}
$$

avec

$\sum_{i} \sum_{p} X_{i, p, m 1, c}-\left(1-x_{1}\right) X_{c} \leq 0$
$\sum_{i} \sum_{p} \sum_{m} X_{i, p, m 2, c}-\left(X_{c m} * x_{1}\right) \leq 0$

où

$p_{m, c}$ : profit fait en choisissant la mesure $\left(p_{m 2, c}\right)$ ou pas $\left(p_{m l, c}\right)$

$i$ : activité culture 


\section{Contrôle des pollutions diffuses}

$l:$ activité élevage

$p$ : niveau d'intensification des pratiques (intensive, moyenne, extensive)

$m$ : pratiques standard $m_{1}$ ou avec une mesure agro-environnementale $m_{2}$

$c$ : commune

$X_{c}:$ surface agricole utile de la commune

$X_{i, p, m, c}$ : superficie de l'activité (ha) par commune $c$ pour la culture $i$, intensification $p$ et pratique standard $m_{1}$ ou avec mesure $m_{2}$

$x_{1}$ : variable binaire permettant de passer d'une pratique standard à une pratique avec mesure

$y_{i, p, m}$ : rendement de l'activité [tonnes de grains ou matière sèche $\mathrm{ha}^{-1}$ ] par culture, niveau d'intensification et type de pratique

$p_{i}$ : prix de la culture $\mathrm{i}\left(€ . \mathrm{ha}^{-1}\right), p_{l}$ : prix pour la viande ou lait $\left(€ . \mathrm{kg}^{-1}\right)$

$c v_{i, p, m}$ : coûts variables de production par culture, intensification $p$ et pratique standard ou avec mesure $\left(€\right.$. ha $\left.^{-1}\right)$

$C\left(X_{m 2}\right)$ : coût de la mesure $\left(€ \cdot\right.$ ha $\left.^{-1}\right)$

$i n c_{m 2}$ : incitation/compensation nécessaire pour avoir l'activité avec la mesure agroenvironnementale $m_{2}$ adoptée (dans la solution de base)

Le niveau optimal de la surface contractant une mesure est trouvé en dérivant le second terme de l'équation (3):

$\frac{\partial \pi_{c}}{\partial X_{m 2, c}}=i n c_{m 2}-C_{m 2, c}^{\prime}\left(X_{m 2, c}\right)=0$

où $C^{\prime}\left(X_{m 2}\right)$ représente le coût marginal de la mesure. L'équation 2 montre que lorsque la variable de décision (activité avec mesure) apparaît dans la solution optimale, l'incitation et le coût marginal s'annulent mutuellement.

Les contraintes prises en compte (annexe 1) ont été les contraintes de mesure, les contraintes de surface agricole, de surface irrigable, de prairies permanentes, de rotations et des contraintes d'élevage (alimentation, gestion du troupeau).

Par ailleurs, si les valeurs marginales (shadow costs) indiquent l'éloignement de chaque activité avec mesure pour entrer dans la solution optimale, elles n'indiquent pas quel serait leur niveau optimal si elles entraient dans la solution, ni n'indiquent comment le niveau optimal des autres activités actuellement dans la solution seraient affectées. Pour déterminer exactement quels changements se produiraient, il est donc nécessaire de modifier le modèle puis de le résoudre de nouveau, ce qui est fait pour des niveaux d'incitations croissants. Les cycles d'optimisation au niveau du bassin versant montrent alors les substitutions et les courbes de coûts d'implémentation illustrant ainsi pour chaque mesure et pour les différentes communes, la relation coûts-surface implémentée. Les résultats du modèle révèlent aussi les changements d'utilisation du sol. Les coûts totaux sur la période de simulation de 25 ans ont été calculés avec un taux d'actualisation de 0,05 .

\section{Résultats pour l'évaluation de l'efficacité}

Les résultats de simulation avec SWAT montrent que, dans les conditions actuelles de la zone Gers amont, la pollution par les pesticides peut être réduite en mettant en place des mesures environnementales. 
RECHERCHES

Pour une mesure donnée, l'efficacité varie néanmoins largement entre sous-bassins (figure 4). Les meilleurs résultats (plus grande réduction) pourraient être atteints par certaines mesures telles que la création de bandes tampons herbacées le long des ruisseaux (scénarii 1.1, 1.2, 1.3 et 2.2). Ces mesures ont un effet significatif sur la réduction des pesticides dans les eaux de surface, variant toutefois selon qu'elles sont appliquées sur les zones prioritaires ou sur l'ensemble de la zone Gers amont (tableau 2). L'accroissement de la superficie des prairies en remplacement des terres arables (scénario 2.7) a également un effet significatif positif.

Les résultats du modèle sont en conformité avec ceux des études précédentes par Lacas et al. (2005), Popov et al. (2006),
Borin et al. (2010). Le passage du désherbage chimique au désherbage mécanique (scénario 1.4 et 2.4) pourrait aussi avoir un effet immédiat sur les charges en pesticides. L'effet est renforcé néanmoins lorsque la mesure est appliquée sur l'ensemble de la zone Gers amont (scénario 2.4). Ces résultats pourraient s'expliquer par le fait que les types de produits chimiques qui sont détectés à concentrations élevées sont principalement des herbicides (en particulier le S-Métolachlore et le Glyphosate) ou leurs métabolites.

D'autre part, on peut noter l'inefficacité relative d'autres changements de pratiques, comme l'utilisation de cultures intermédiaires pièges à nitrates sur sols nus (scénario 1.6 et 2.6) ou l'allongement de la rotation des cultures (scénario 1.5 et 2.5).

Tableau 2. Analyse de l'efficacité (résultats de simulation avec le Modèle SWAT), coûts totaux et ratios CE

\begin{tabular}{|c|c|c|c|c|c|c|c|}
\hline $\begin{array}{c}\text { Mise en } \\
\text { place }\end{array}$ & Scénario & Mesures & $\begin{array}{l}\text { Superficie } \\
\text { (ha) }\end{array}$ & $\begin{array}{l}\text { Concentration } \\
\text { totale }\left(\mu \mathrm{g} . I^{-1}\right) \\
\text { (exutoire) ** }\end{array}$ & $\begin{array}{c}\text { Efficacité } \\
\text { (\% réduction) }\end{array}$ & $\begin{array}{c}\text { Coûts } \\
\text { totaux }(€)\end{array}$ & $\begin{array}{c}\text { ratios CE } \\
\qquad\left(* 10^{4}\right)\end{array}$ \\
\hline \multirow{7}{*}{$\begin{array}{c}\text { Uniquement } \\
\text { sur les zones } \\
\text { prioritaires } \\
\text { (scenarii 1) }\end{array}$} & & & & 1.2 & \multicolumn{3}{|c|}{ Scénario initial* } \\
\hline & 1.1 & BS10_ZP_ext & 141 & 0.85 & 29 & 1021979 & 292 \\
\hline & 1.2 & BS20_ZP & 156 & 0.78 & 35 & 1002726 & 239 \\
\hline & 1.3 & BS20_ZP_ext & 280 & 0.72 & 40 & 1795194 & 374 \\
\hline & 1.4 & MW_ZP & 9658 & 0.96 & 20 & 18136446 & 7557 \\
\hline & 1.5 & LR_ZP & 9256 & 1.19 & 0.5 & 11372194 & 113722 \\
\hline & 1.6 & CC_ZP & 9658 & 1.18 & 1 & 7012277 & 35061 \\
\hline \multirow{6}{*}{$\begin{array}{l}\text { Mesure } \\
\text { appliquée } \\
\text { sur toute } \\
\text { la zone } \\
\text { Gers amont } \\
\text { (scenarii 2) }\end{array}$} & & & & 1.2 & \multicolumn{3}{|c|}{ Scénario initial } \\
\hline & 2.2 & BS20_GA & 950 & 0.66 & 45 & 4601327 & 852 \\
\hline & 2.4 & MW_GA & 24127 & 0.38 & 68 & 37536281 & 4578 \\
\hline & 2.5 & LR_GA & 24599 & 1.18 & 1 & 21238345 & 106192 \\
\hline & 2.6 & CC_GA & 24127 & 1.17 & 2 & 15929465 & 53098 \\
\hline & 2.7 & SGL_GA*** & 16289 & 0.66 & 45 & 125629621 & 23265 \\
\hline
\end{tabular}

Note : * Scénario de référence (i.e. avant implémentation des mesures) : I'implémentation de la mesure BS10 (bandes tampons de 5 mètres de chaque côté des cours d'eau) qui est obligatoire a donc été considérée comme déjà mise en place.

** Somme des molécules (moyenne annuelle calculée à partir des concentrations journalières à l'exutoire du bassin versant au point de mesure de Roquelaure). Concentration pour le scénario de référence : $1.2 \mu \mathrm{g} . \mathrm{I}^{-1}$.

*** Implémentation pour un niveau d'incitation de $600 €$. ha $^{-1}$ 
Ces résultats sont conformes à ce qui est effectivement observé dans les zones du bassin versant où ces mesures ont été appliquées depuis quelques années avec des systèmes de culture déjà diversifiés sans aucun réel changement observé quant aux concentrations en pesticides dans les analyses d'eau. Enfin, nous pouvons constater que la concentration objective de $0.5 \mathrm{mg} .1^{-1}$ n'est jamais atteinte, exceptée pour un scénario (scénario 2.4). Atteindre les objectifs de la DCE nécessiterait donc une combinaison efficace de plusieurs mesures agroenvironnementales qui doivent toutefois être évaluées au préalable.

\section{Résultats pour l'évaluation des coûts}

Pour une mesure donnée, les coûts marginaux calculés et les coûts totaux varient largement entre communes du fait que les changements sont appliqués à différentes cultures, rotations et systèmes de culture (figure 4). En général, les coûts marginaux sont légèrement plus élevés quand les mesures sont mises en place uniquement sur les zones prioritaires par rapport à une application sur l'ensemble de la zone Gers amont (tableau 2). Les coûts totaux pour les communes sont calculés par l'intégration des coûts marginaux calculés pour des surfaces d'implémentation croissantes jusqu'à ce que la mesure soit appliquée à l'ensemble de la superficie du territoire Gers amont où elle est susceptible d'être mise en place ${ }^{12}$. Lorsque nous comparons

12. Les coûts totaux pourraient être calculés pour différents niveaux de mise en place. De même, pourrait être évaluée l'efficacité de la mesure appliquée sur une surface donnée. Se pose alors la question sur l'endroit où appliquer une mesure pour un coût minimum et une efficacité maximale, et quelle est la superficie minimale nécessaire pour atteindre les objectifs de réduction des pesticides. Des simulations exécutées pour différents niveaux de surface avec mesures pourraient aider à répondre à ces questions. les coûts totaux entre les mesures, nous notons que certaines mesures, en raison de leurs coûts moyens par hectare implémenté (cultures pièges) ou de la surface mise en place (bandes enherbées) sont relativement peu coûteuses au niveau du bassin versant.

\section{Analyse coût-efficacité}

Nous avons indiqué que pour une mesure donnée, tant le coût d'implémentation que l'efficacité variait spatialement et en conséquence les ratios cout-efficacité $R$. La cartographie de ces coûts, efficacités et ratios $R$ par sous-bassin révèle ainsi les emplacements où la mise en place d'une mesure sera la plus efficiente (figures $5 a, 5 b, 5 c$, p. 137-139). La somme des coûts totaux par sous-bassin et l'efficacité à l'exutoire du bassin versant permettent aussi de calculer des ratios CE pour l'ensemble du bassin mettant ainsi en évidence les mesures susceptibles de conduire aux meilleurs résultats et aux coûts les plus bas (tableau 2).

Les bandes tampons (mesures BS10_ ZP_ext, BS20_ZP, BS20_ZP_ext et BS20_ GA) sont ainsi les mesures qui peuvent être considérées comme les plus « coûtefficaces » avec un très faible ratio $\mathrm{CE}$ (de $292 \times 10^{4}$ à $852 \times 10^{4}$ ) en comparaison à d'autres mesures comme l'allongement des rotations (mesures LR_ZP et LR_GA) avec des ratios bien plus élevés (respectivement $113722 \times 10^{4}$ et $106192 \times 10^{4}$ ) ou les cultures pièges (mesures CC_ZP et CC_GA) avec des taux respectifs de 35061 $\mathrm{x} 10^{4}$ et $53098 \times 10^{4}$.

L'effet des bandes tampons a été largement rapporté dans la littérature comme étant un moyen de réduire les transferts de pesticides par ruissellement de surface des champs vers les cours d'eau. Bien que cette mesure s'avère être plus coûteuse par hectare mis en place que les autres, son faible ratio CE la met en avant des meilleures mesures coût-efficaces. 
Lorsque cette mesure bandes enherbées est appliquée uniquement sur les zones prioritaires (scenarii 1), on observe qu'avec des surfaces implémentées très voisines, une meilleure efficacité est obtenue en augmentant la largeur de la bande tampon plutôt qu'en l'appliquant sur un réseau hydrographique plus long (scénario 1.2 versus scénario 1.1). En outre, l'implémentation de la mesure BS10_ZP_ ext (scénario 1.1) donne des coûts totaux légèrement plus élevés que celle de la mesure BS20_ZP (scénario 1.2) probablement du fait que les changements sont plus distribués et affectent un éventail plus large de cultures. En conséquence, de part son ratio plus faible, les bandes tampons de 20 mètres de largeur devancent tous les scenarii modélisés. Étendre les bandes tampons élargies à un réseau hydrographique plus long (scénario 1.3) amènerait une meilleure efficacité, mais avec des coûts et finalement un ratio $\mathrm{CE}$ plus élevé qu'avec les deux scenarii précédents. Lorsque nous comparons la même mesure bande enherbée (BS20) appliquée, soit sur la zone prioritaire (scénario 1.2) soit sur l'ensemble de la zone amont (scénario 2.2), les résultats montrent que le scénario 1.2 est nettement plus « coût-efficace ».

Bien qu'avec des résultats similaires concernant la réduction des concentrations en pesticides, le scénario visant à augmenter les surfaces en herbe en remplacement des terres arables (scénario 2.7) a un ratio CE moins favorable en raison d'une augmentation du coût unitaire par hectare et la nécessité d'appliquer une surface plus grande.

Passer du désherbage chimique au désherbage mécanique (scenarii 1.4 et 2.4) pourrait également être considéré comme une mesure coût efficace (tableau 3) en dépit de ses effets négatifs sur l'érosion.

Figure 4. Coûts de mise en place des mesures (coûts moyens, étendue des coûts marginaux et surface totale dédiée à la mesure)

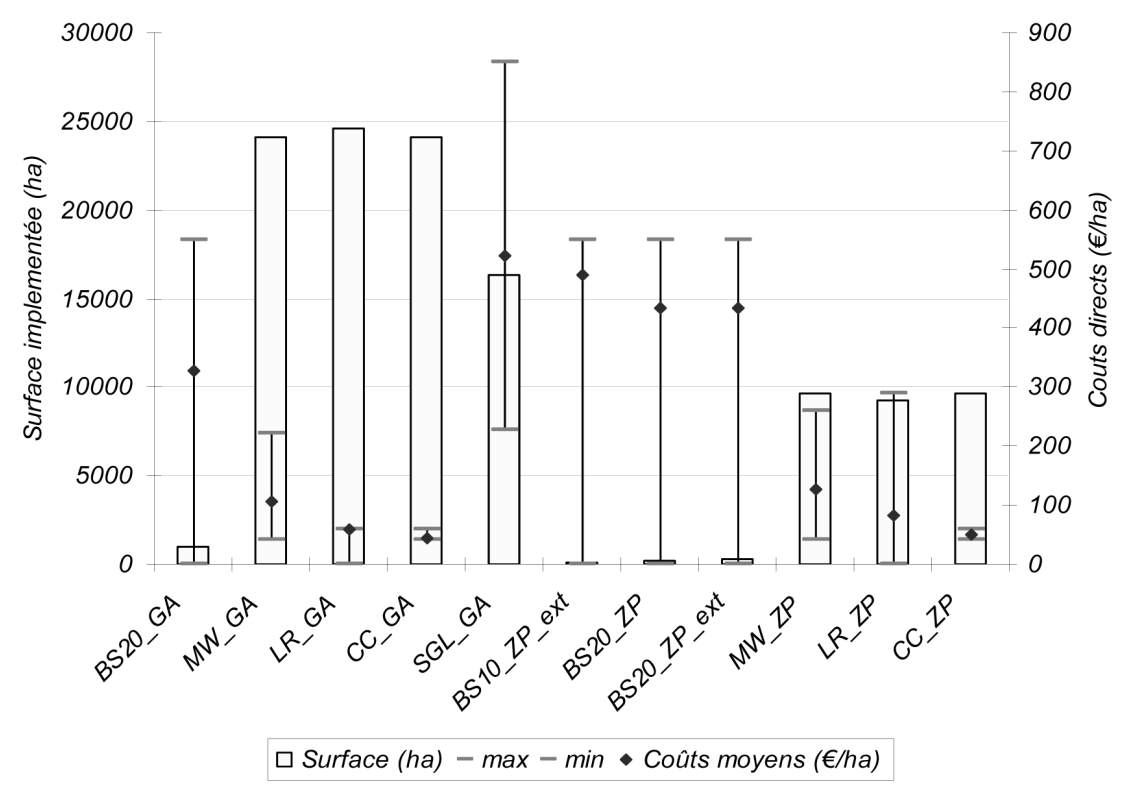

Source : Les auteurs 
Les résultats montrent également qu'appliquer la mesure sur l'ensemble de la zone Gers amont (scénario 2.4) est plus « coût-efficace » que de restreindre son application uniquement aux zones prioritaires (scénario 1.4). L'efficacité de la suppression du désherbage chimique sur toute la superficie cultivée du bassin versant compense d'une certaine façon des coûts bien plus élevés.

Nous devons insister ici sur le fait que l'efficacité se rapporte uniquement à la réduction des pesticides et que certaines autres mesures telles que les cultures pièges (CC_GA et CC_ZP) en comparaison avec la mesure désherbage mécanique ( $\mathrm{MW}_{-}$ GA et MW_ZP), bien qu'ayant un ratio CE beaucoup plus élevé, pourraient avoir un impact favorable sur d'autres pollutions diffuses (azote, phosphore...) ou l'érosion.

La mesure rotation plus longue (LR_ZP et LR_GA) est clairement la moins « coûtefficace» des mesures pour réduire la pollution par les pesticides. Cette mesure est néanmoins la plus largement contractée par les agriculteurs dans la zone Gers amont probablement en raison de coûts d'implémentation très faibles voire même nuls alors qu'elle bénéficie d'un support financier $(137 € / \mathrm{ha})$.

Par ailleurs, les bandes tampons d'une largeur de $10 \mathrm{~m}(2 \times 5 \mathrm{~m})$ bien qu'obligatoires sur zones prioritaires et de ce fait utilisées pour le scénario de base n'ont pas toujours été mises en place. On peut supposer qu'une meilleure application des règlements et en conséquence une plus large implémentation de ces zones enherbées devrait aussi permettre de réduire les concentrations en pesticides dans les eaux de surface.

À partir des résultats obtenus, nous montrons l'inefficacité de plusieurs mesures proposées pour atteindre les objectifs de réduction des concentrations en pesticides malgré des coûts parfois importants. Leur impact sur la pollution de l'eau a été effectivement très limité jusqu'à maintenant, avec de très hauts niveaux de concentrations en pesticides encore mesurés régulièrement dans les analyses d'eau. Des questions se posent alors sur l'efficacité des politiques publiques environnementales suivies par l'État et les Agences de l'eau dans la définition de mesures pouvant recevoir un appui financier au sein de vastes territoires des bassins hydrographiques et/ou de zones prioritaires où les actions devraient se concentrer.

\section{Discussion Avantages et limites de l'approche}

Les objectifs de la présente étude étaient de mettre en évidence comment l'utilisation des terres avec des systèmes de culture différents, les caractéristiques des parcelles ainsi que leur localisation spatiale au sein d'un bassin versant peuvent affecter et les coûts et l'efficacité des mesures environnementales et par conséquent leur coût-efficacité (ou coût-inefficacité).

Nous avons essayé par la modélisation agro-hydrologique de démontrer que les zones avec les plus hautes pressions ne sont pas toujours les zones qui contribuent le plus à la pollution dans les cours d'eau. En agrégeant les ressources à la commune et en modélisant les variables regroupées comme une seule grande exploitation agricole, nous avons tenté de surmonter le problème récurrent de disponibilité des données. Même si la définition des objectifs environnementaux de la DCE (restauration du bon état écologique) et leur suivi (seuils limites de concentration en pesticides et méthodes de détection) peuvent être discutés, les programmes de politique environnementale pour réduire l'exposition aux pesticides de l'eau répondent à de véritables préoccupations. Les principales questions à traiter se rapportent à l'identification des principales sources de pollution (ponctuelles et diffuses) et au problème de leur contribution à la qualité de 
RECHERCHES

Jean-Marie LESCOT, Paul BORDENAVE, Odile LECCIA, Kevin PETIT

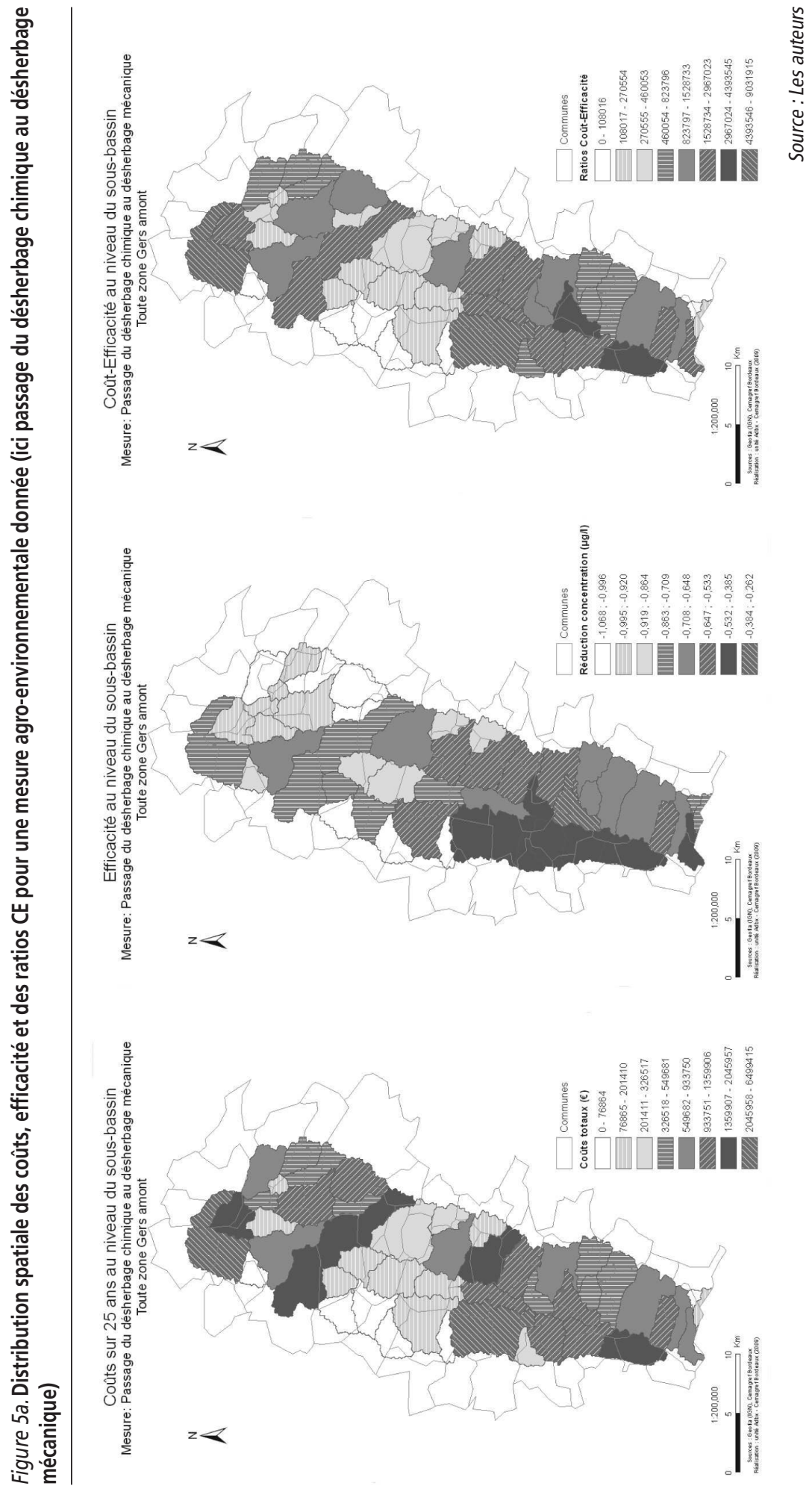

Économie Rurale 333/JanVier-FÉVrier 2013 • 137 
Contrôle des pollutions diffuses

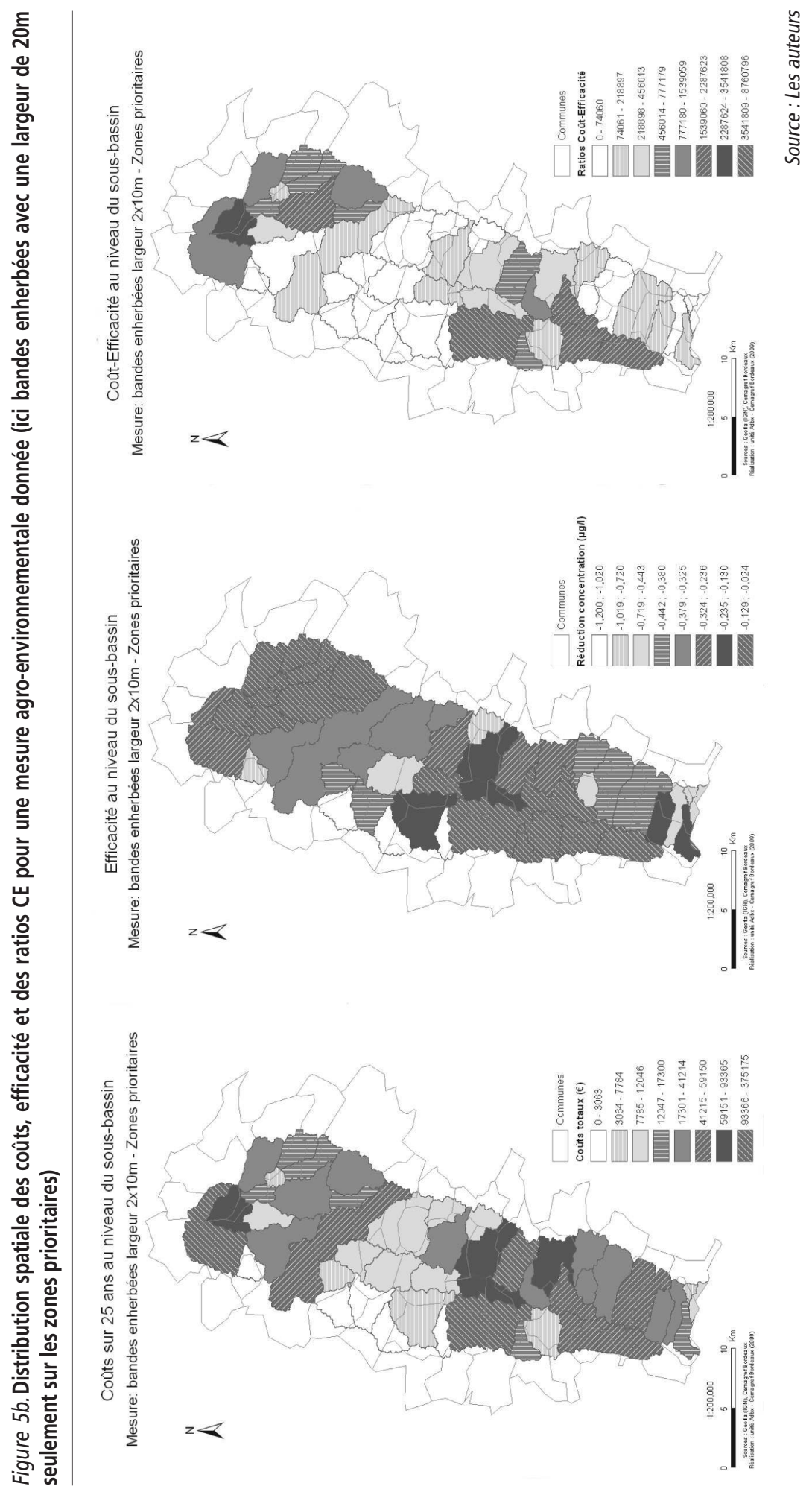

138 • Économie Rurale 333/Janvier-Février 2013 
RECHERCHES

Jean-Marie LESCOT, Paul BORDENAVE, Odile LECCIA, Kevin PETIT

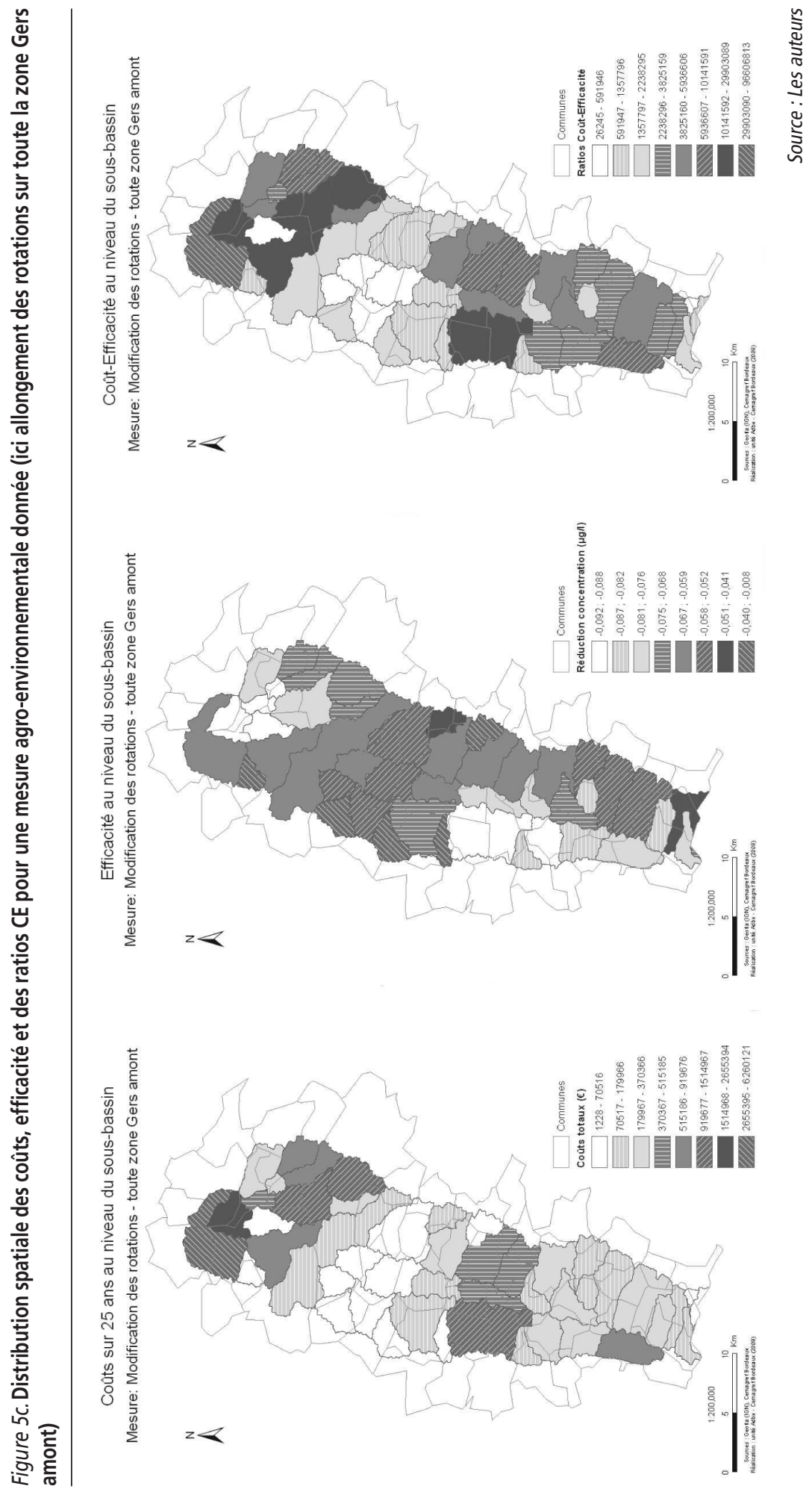

Économie Rurale 333/JanVier-Février 2013 • 139 
l'eau (contribution de l'agriculture et des pratiques, utilisation des pesticides dans les jardins familiaux, entretien des fossés et chemins de fer...). Nous pouvons aussi considérer que l'application de la nouvelle Directive pesticides (2009/128/CE) limitera considérablement la pollution ponctuelle et permettra ainsi une utilisation responsable plus étendue.

La sélection des meilleures zones pour la mise en œuvre des mesures est par ailleurs sujette à des incertitudes parce que les zones identifiées par la pression de pollution peuvent ne pas être toujours les meilleures localisations. Néanmoins, dans certains cas les incertitudes devraient être acceptées compte tenu des connaissances scientifiques disponibles à ce jour et dans d'autres cas pourraient être réduites par l'utilisation appropriée de données fiables associée aux approches habituelles de calibrage, de validation et d'analyse de sensibilité. L'analyse de sensibilité (prise en compte de la manière dont les erreurs de données d'entrée affectent les erreurs de sortie) pour les évaluations hydrologique et économique conduit à une gamme de valeurs déterminée par la façon dont sont traités les paramètres. Si l'analyse de sensibilité n'a été pas pleinement exécutée dans le cadre de cette étude ${ }^{13}$, elle devrait néanmoins être réalisée dans l'avenir sur les valeurs de certains paramètres économiques comme le prix des intrants et surtout celui des productions. En effet, en périodes de prix élevés des produits agricoles, les compensations pour l'application de ces mesures peuvent devenir moins attrayantes. Il est également possible d'établir une gamme de valeurs du ratio CE en divisant les coûts les plus faibles obtenus par les efficacités les plus grandes et les valeurs les plus élevées de coûts par les

13. L'analyse de sensibilité a été réalisée sur certains paramètres et seulement pour la modélisation agro hydrologique. valeurs d'efficacité les plus basses. Ce faisant, nous pouvons facilement identifier l'intérêt des différentes mesures (avec une plage d'incertitude) pour une discussion rationnelle avec les acteurs.

Nous devons enfin souligner aussi que seuls les coûts directs de mise en œuvre des mesures ont été ici considérés, laissant de côté tous les autres coûts, tels que les coûts indirects et les coûts de transaction. Si l'évaluation des coûts indirects se trouve être difficile, nous pouvons néanmoins raisonnablement supposer des coûts administratifs similaires pour toutes les mesures. Par ailleurs, l'ACE pourrait ne pas être aussi pertinente quand les mesures génèrent des résultats secondaires et/ou indirects. Si nous considérons en même temps, par exemple, la réduction de la pollution par les pesticides et par les nitrates, l'ACE n'est plus appropriée. L'analyse multicritères peut alors être un instrument supplémentaire utile pour sélectionner ces mesures (en utilisant les sorties du modèle SWAT pour plusieurs variables telles que les nitrates, le phosphore, l'érosion...). Instrument simple et efficace d'évaluation, l'ACE est aussi un outil éducatif et de communication résumant les résultats en un seul indicateur quantifiable. Les résultats présentés graphiquement sont utiles dans une évaluation intégrée participative (Dahinden et al., 2000) en indiquant la variabilité des ratios CE à l'intérieur d'une zone d'action. L'implication et la participation précoce des acteurs dans le processus de sélection des mesures sont à notre avis des éléments importants pour promouvoir efficacement l'acceptabilité et la participation aux programmes de réduction des usages et de limitation des transferts des pesticides.

$$
\text { * }
$$

Le cadre présenté ici pourrait être utile dans l'analyse ex-ante mais aussi ex-post de programmes de restauration de la qualité de l'eau (objectifs DCE ou Grenelle 
de l'environnement), l'objectif étant de trouver les changements de cultures et de pratiques qui contribueront le plus à la réalisation des objectifs à un coût minimum. Griffin et Bromley (1982) et Shortle et Dunn (1986) ont démontré de manière théorique que les systèmes d'incitations influant les décisions de production peuvent être utilisés pour contrôler efficacement la pollution diffuse. Les incitations financières encourageant l'adoption de mesures associées à un ensemble de bonnes pratiques sont ainsi préconisées comme un moyen d'alléger la charge financière des producteurs individuels augmentant ainsi la probabilité d'adoption de mesures pour lesquels les avantages sociaux sont plus élevés que les coûts privés de réduction (OCDE, 1989).

Parce que les taxes sont souvent politiquement irréalisables en raison des taux élevés nécessaires pour induire des changements de comportement, les subventions visant à favoriser adoption de mesures sont largement utilisées par les politiques publiques. Elles sont cependant aussi incompatibles désormais avec la réduction des dettes publiques, objectif majeur de la plupart des gouvernements actuellement. L'inconvénient principal de ces programmes dotés de fonds limités réduisant donc de fait leur portée est in fine leur coût inefficacité qui en résulte. Le bon choix d'un programme de réduction de la pollution par les pesticides pourrait être alors un système de gestion d'incitations pour la mise en place de mesures précisées localement. La structure d'incitation idéale serait ainsi composée d'une prime pour chaque mesure définie en relation avec l'emplacement de l'exploitation, impliquerait une combinaison de subventions et de taxes et serait spécifique au (sous-)bassin. Des instruments de conception moins sophistiqués ont été largement appliqués jusqu'à présent sans effets tangibles.

Une partie du travail présenté ici a été développée pendant le projet Concert'eau. Ce projet financé par le programme européen Life Environnement et l'Agence de l'eau Adour Garonne avait pour objectif d'établir une plate forme collaborative comme outil d'aide à la décision pour les acteurs de l'eau et de l'agriculture dans le choix des scenarii de changement de pratiques agricoles et l'introduction de mesures de réduction des pressions par les pesticides.

\section{REFERENCES BIBLIOGRAPHIQUES}

Alkan Olsson J., Anderson L. (2007). Possibilities and problems with the use of models as a communication tool in water resource management. Water Resour manage; $\mathrm{n}^{\circ} 21$, p. 97-110.

Arnold J. G., Fohrer N. (2005). SWAT2000: current capabilities and research opportunities in applied watershed modelling, Hydrol. Process, $\mathrm{n}^{\circ} 19$, p. 563-572.

Borin M., Passoni M., Thiene M., Tempesta T. (2010). Multiple functions of buffer strips in farming areas. European Journal of Agronomy, vol. 32, ${ }^{\circ} 1$, p. 103-111.
Brooke A., Kendrick D., Meeraus A. (1988). GAMS: A User's Guide. The Scientific Press, South. San Francisco, CA.

Brouwer R., De Blois C. (2008). Integrated modelling of risk and uncertainty underlying the cost and effectiveness of water quality measures. Environmental Modelling \& Software, vol. 23, n7, p. 922-937.

Brouwer R., Hofkes M. (2008). Integrated hydro-economic modelling: Approaches, key issues and future research directions. Ecological Economics, vol. 66, n¹, p. 1622.

Économie Rurale 333/Janvier-Février 2013 • 141 
Buysse J., van Huylenbroeck G., Lauwers L. (2007). Normative, positive and econometric mathematical programming as tools for incorporation of multifunctionality in agricultural policy modeling. Agriculture, Ecosystems, and Environment, vol. 120, $\mathrm{n}^{\circ} 1$, p. 70-81.

Centre de Gestion Conseil Gascogne Adour, Référentiel, 2005 et Observatoire économique des exploitations agricoles du Gers (2005).

Chambres d'agriculture de Midi-Pyrénées, Institut de l'élevage (2006). Les systèmes de production bovins viande en Midi-Pyrénées et Languedoc-Roussillon. Novembre, 13 fiches.

Commission Regulation (EC) No 1122/2009 laying down detailed rules for the implementation of Council Regulation (EC) No. 73/2009 as regards cross-compliance, modulation and the integrated administration and control system, under the direct support schemes for farmers. Official Journal L 316, 02/12/2009 P. 0065 - 0112.

Directive 2000/60/EC establishing a framework for the Community action in the field of water policy. Official Journal of the European Communities L327: 1-72.

Nations Unies; United Nations Economic Commission for Europe (UNECE); 1998. Convention on Access to Information, $\mathrm{Pu}-$ blic Participation in Decision-making and Access to Justice in Environmental Matters; Aarhus, Denmark, Fourth Ministerial Conference in the 'Environment for Europe' process 25 June 1998.

Dahinden U., Querol C., Jäger J., Nilsson M. (2000). Exploring the use of computer models in participatory integrated assessment- experiences and recommendations for further steps. Integrated Assessment, $\mathrm{n}^{\circ} 1$, p. 253-266.

Day R. H. (1963). On aggregating linear programming models of production. Journal of Farm Economics, n45, p. 797-813.

Dickinson W.T., Rudra R.P., Wall G. J. (1990). Targeting remedial measures to control nonpoint source pollution. Journal of the American Water Resources Association, vol. 26, $\mathrm{n}^{\circ} 3$, p. 499-507.
Directive 91/676/EEC concerning the protection of waters against pollution caused by nitrates from agricultural sources. Official Journal of the European Communities, L 375 , p. 1-8.

Directive 2000/60/EC establishing a framework for the Community action in the field of water policy. Official Journal of the European Communities, L327, p. 1-72.

Directive 2009/128/EC establishing a framework for Community action to achieve the sustainable use of pesticides. Official Journal of the European Communities, L 309, p. 71-86.

European Commission (2003). Fact sheet; Agriculture and the environment. Directorate General for Agriculture and Rural Development, December.

Feuz D. M., Skold M. D. (1991). Typical farm Theory in Agricultural Research. Journal of Sustainable Agriculture, $\mathrm{n}^{\circ}$ 2, p. 43-58.

Gascuel-Odoux C., Aurousseau P., Durand P., Ruiz L., Molenat J. (2010). The role of climate on inter-annual variation in stream nitrate fluxes and concentrations. Science of the Total Environment, vol. 408, n²3, p. 5657-5666.

Gassman P. W., $\quad$ Reyes M. R., Green C. H., Arnold J. G. (2007). The Soil and Water Assessment Tool: historical development, applications and future research directions. Transactions of the ASAE 50, p. 1211-1250.

Griffin, R. C., Bromley, D. W. (1982). "Agricultural Runoff as a Nonpoint Externality: A Theoretical Development", American Journal of Agricultural Economics, 64. 1982, p. 547-552.

Lacas J. G., Voltz M., Gouy V., Carluer N., Gril J. J. (2005). Using grassed strips to limit pesticide transfer to surface water: a review. Agronomy for Sustainable Development, $n$ 25, p. 253-266.

Lee L. K. (1998). Groundwater Quality and farm Income: What Have we learned? Review of Agricultural Economics, vol. 20, $\mathrm{n}^{\circ} 1$, p. 168-185.

Morin S, Bottin M, Mazzella N, Macary F, Delmas F, Winterton P, Coste M. (2009). Linking diatom community structure to 
RECHERCHES

pesticide input as evaluated through a spatial contamination potential (Phytopixal): A case study in the Neste river system (SouthWest France). Aquatic Toxicology, vol. 94, $\mathrm{n}^{\circ} 1$, p. 28-39.

Mc Carl GAMS User Guide, Version 23.3 (2009). Bruce A. Mc Carl., Meeraus A., van der Eijk P., Bussieck M., Dirkse S., Steacy P., GAMS Development Corporation.

Neitsch S. L., Arnold J. G., Kiniry J. R., Srinivasan R., Williams J. R. (2005). Soil and Water Assessment Tool Theoretical Documentation, version 2005. Temple, TX: Grassland, Soil and Water Research Laboratory, Agricultural Research Service.

Nations Unies, 2000, United Nations, Water Management: Public Participation and Compliance with Agreements; ECE/UNEP Network of Experts in Public Participation and Compliance (2000), p. 57.

O'Callaghan J.R. (1996). Land Use, the interaction of economics, ecology and hydrology. London, Chapman and Hall.

OECD (1989). Agricultural and Environmental Policies: Opportunities for Integration. Paris, OECD.
Popov V. H, Cornish P. S., Sun H. (2006). Vegetated biofilters: The relative importance of infiltration and adsorption in reducing loads of water-soluble herbicides in agricultural runoff. Agriculture, Ecosystems \& Environment, vol. 114, issues 2-4, p. 351-359.

Références technico-économiques en systèmes de grandes cultures (2006). Chambre d'agriculture Midi-Pyrénées, Conseil régional Midi-Pyrénées; résultats 2005.

Roa-García M. C., Weiler M. (2010). Integrated response and transit time distributions of watersheds by combining hydrograph separation and long-term transit time modeling. Hydrology and Earth System Sciences, vol. 7, $\mathrm{n}^{\circ} 1$, p. 1-32.

Shortle, J. S., Dunn, J. W. (1986). "The Relative Efficiency of Agricultural Source Water Pollution Control Policies", American Journal of Agricultural Economics, 68. 1986, p. 668-677.

Ullrich A., Volk M. (2009). Application of the Soil and Water Assessment Tool (SWAT) to predict the impact of alternative management practices on water quality and quantity. Agricultural Water Management, vol. 96, n'8, p. 1207-1217. 


\section{ANNEXE}

\section{Modèle bio-économique pour l'estimation des coûts}

$$
\begin{aligned}
& \operatorname{Max} \Pi_{c}(X) \quad \forall c ; \Pi_{c}(X)=\pi_{m 1, c}+\pi_{m 2, c} \\
& \text { avec } \\
& \pi_{m 1, c}=\sum_{i} \sum_{p}\left(y_{i, p, m \mathrm{l}, c} \times p_{i}-c v_{i, p, m \mathrm{l}}\right) \times X_{i, p, m \mathrm{l}, c}+\sum_{l} \sum_{p}\left(y_{l, p} \times p_{l}-c v_{l, p}\right) \times X_{l, p, c} \\
& \pi_{m 2, c}=\left[\sum_{i} \sum_{p} X_{i, p, m 2, c} \times\left(y_{i, p, m 2} \times p_{i}-c v_{i, p, m 2}\right)\right]+\left[i n c_{m 2, c} \times X_{m 2, c}-C_{m 2, c}\left(X_{m 2, c}\right)\right]
\end{aligned}
$$

$c$ : commune (commune ayant au moins $10 \%$ de sa surface à l'intérieur du basin versant)

$i$ : activités cultures

$l:$ activité élevage

$p$ : niveau d'intensité de la pratique (intensif, moyen, extensif)

$m$ : pratiques standard $m_{1}$ ou avec la mesure agri environnementale $m_{2}$

$X_{i p m c}$ : surface de l'activité pour la culture $i$, intensité $p$ et la pratique $k$ (ha) à l'intérieur de la commune $c$

$X_{i p m}$ : rendement de l'activité (tonne de grains or Matière Sèche par ha) par culture, niveau d'intensification et type de pratique

$p_{i}$ : prix du produit de la culture $i\left(€ . \mathrm{ha}^{-1}\right), p_{l}$ : prix de la viande ou lait $\left(€ \cdot \mathrm{kg}^{-1}\right)$

$c v_{i, p, m}:$ coûts variables de production par culture, niveau d'intensification et type de pratique $\left(€ \cdot\right.$ ha $\left.^{-1}\right)$

inc $c_{m}$ : incitation $\left(€ \cdot \mathrm{ha}^{-1}\right)$

Sous contraintes

\section{Contraintes de surface}

$\sum_{i} \sum_{p} \sum_{m} X_{i, p, m, c} \leq X_{c} \quad \forall c$

$X_{c}$ : surface agricole utile de la commune $c$ incluse dans le bassin versant

\section{Contraintes de mise en place des mesures}

$\sum_{i} \sum_{p} \sum_{m} X_{i, p, m_{1}, c}-\left(1-x_{1}\right) X_{c} \leq 0 \quad \forall c$

$X_{c}$ : surface agricole de la commune $c$ incluse dans le bassin versant

$\sum_{i} \sum_{p} \sum_{m} X_{i, p, m_{2}, c}-\left(X_{m, c} * x_{1}\right) \leq 0 \quad \forall c$

$X_{m, c}$ : surface agricole de la commune concernée par la mesure; $x_{l}$ : variable binaire autorisant le passage de la pratique standard à la mesure agro-environnementale.

\section{Contraintes d'irrigation}

$\sum_{i} \sum_{p} \sum_{m} X_{i, p, m, c} \leq X i r_{c} \quad \forall c$

$i$ : cultures irriguées ; $X i r_{c}$ : surface agricole irrigable de la commune. 


\section{Contraintes prairies permanentes}

$$
\sum_{p} X_{i, p, m_{1}, c}-X_{i^{\prime}, c} \leq \varepsilon \quad \forall c
$$

$i^{\prime}$ : prairies permanentes; $X_{i, c}$ : surface agricole utile en prairies permanentes sur la commune c (estimée à partir du croisement de diverses sources RA2000, Landcover 2000, Landstat TM 2006).

\section{Contraintes de rotation}

L'utilisation du sol est modélisée en passant des rotations aux successions culturales. Ainsi nous considérons que, par exemple pour une rotation Tournesol-Blé, la moitié de la surface de la rotation est en tournesol alors que l'autre moitié est en blé. Deux rotations sur les onze sont présentées ici à titre d'exemple).

* Rotation Tournesol-Blé tendre

$\sum_{i} \sum_{p} \sum_{m} X_{i, p, m}-\sum_{i^{\prime}} \sum_{p} \sum_{m} X_{i, p, m} \leq 0$

$\sum_{i} \sum_{p} \sum_{m} X_{i, p, m, c_{1}}+\sum_{i^{\prime}} \sum_{p} \sum_{m} X_{i, p, m, c_{1}} \leq X_{c_{1}}$

$\sum_{i^{\prime \prime}} \sum_{p} \sum_{m} X_{i^{\prime \prime}, p, m, c_{1}}=\varepsilon$

$i$ : blé d'hiver et printemps and i': tournesol;

$X_{c l}$ : surface de la commune avec la rotation 1 dans le basin versant

$i ”$ : autres cultures sur le basin versant non incluses dans la rotation standard

* Rotation Maïs-Blé tendre-Tournesol-Blé tendre

$$
\begin{aligned}
& \sum_{i} \sum_{p} \sum_{m} X_{i, p, m}-0.5 \times \sum_{i^{\prime}} \sum_{p} \sum_{m} X_{i^{\prime}, p, m} \leq 0 \\
& \sum_{i} \sum_{p} \sum_{m} X_{i, p, m, c}+\sum_{i^{\prime}} \sum_{p} \sum_{m} X_{i^{\prime}, p, m, c} \leq X_{c_{2}} \\
& \sum_{i^{\prime \prime}} \sum_{p} \sum_{m} X_{i^{\prime \prime}, p, m, c}=\varepsilon
\end{aligned}
$$

$i$ : blé d'hiver et printemps and $i$ ' : maïs sec, maïs irrigué, maïs fourrage, tournesol

$X_{c 2}$ : surface de la commune avec la rotation 2 dans le basin versant

$i$ ": autres cultures sur le basin versant non incluses dans la rotation standard

\section{Contraintes mesure rotation plus longue}

$\sum_{i} \sum_{p} \sum_{k 1} X_{i, p, k 1, c}-\left(1-x_{2 i}\right) X_{c} \leq 0 \quad \forall c$

$\sum_{i} \sum_{p} \sum_{m 2} X_{i, p, m 2, c}-\left(X_{m, c} * x_{2 i}\right) \leq 0 \quad \forall c$

$\sum_{i} x_{2 i} \geq 4$

$X_{c}$ : surface agricole utile de la commune

$X_{m, c}$ : surface de la commune concernée par la mesure

$x_{2 i}$ : variable binaire pour chaque culture 


\section{Contrôle des pollutions diffuses}

\section{Contraintes élevage}

*Gestion du troupeau

$\sum_{p} X_{l, p, c} \leq \hat{X}_{l, c} \quad \forall c$

$l$ : vaches laitières, vaches allaitantes

$X_{l, p, c}$ : nombre de têtes dans la commune (variable entière)

$\hat{X}_{l, c}$ : nombre de têtes estimé à partir du recensement agricole (RA 2000)

* Catégories du bétail

- vaches laitières

$\sum_{l} \sum_{p} X_{l, p, c}-0.47 * X_{l, p, c} \leq 0 \quad \forall c$

$l$ : veaux +

$l$ : vaches laitières

$X_{l, p, c}$ : activités pour les vaches laitières (vente de veaux + , élevage génisses 12 ou 24 mois, remplacement par les génisses)

$\sum_{l} \sum_{p} X_{l, p, c}-0.47 * X_{l, p, c} \leq 0 \quad \forall c$

$l$ : vaches laitières, $l$ ': veaux $\hat{\delta} ; X_{l^{\prime}, p, c}$ : activités pour les vaches laitières (vente de veaux $\hat{\partial}$, élevage broutards 6 ou 12 mois)

- vaches allaitantes

$\sum_{l} \sum_{p} X_{l, p, c}-0.47 * X_{l, p, c} \leq 0 \quad \forall c$

$l$ ': veaux $\hat{o}$ et + , $l$ : vaches allaitantes; $X_{l, p, c}$ : activités pour les vaches allaitantes (vente de veaux $\hat{\sigma}$ et $\phi$, engraissement veaux 6 et 12 mois)

- Vaches de réforme

$X_{l_{2}, c}-0.15 * \sum_{p} X_{l, p, c} \leq 0 \quad \forall c$

$X_{l_{2}, c}$ : activité vente des vaches de réforme $X_{l, p, c}$ : vaches

- Remplacement du troupeau

$0.15 * X_{l, p, c}-X_{l_{3}, c}-X_{l_{4}, c} \leq 0 \quad \forall c$

$X_{l_{4}, c}$ : achat de vaches laitières; $X_{l_{3}, c}$ :remplacement par génisses

* Alimentation du bétail

$\sum_{l} \sum_{p} X_{l, p, c} * f_{l, p}-\sum_{i} \sum_{p} \sum_{m} X_{i, p, c} * y_{i, p, m} \leq 0 \quad \forall c$

$l$ : catégories de bétail (vaches laitières, vaches allaitantes, vaches de réforme, génisses 12 mois, génisses 24 mois, veaux 6 mois); $f_{l, p}$ : besoins alimentaires du bétail par catégorie et niveau d'intensification; $i$ : prairie permanente, prairie temporaire, maïs fourrage;

$y_{i p k}$ : rendement de l'activité [tonne de grains or Matière Sèche par ha] par culture, niveau d'intensification et type de pratique. 